\title{
Total Synthesis of WS9326A, a Potent Tachykinin Antagonist from Streptomyces violaceoniger ${ }^{1)}$
}

\author{
Nobuharu Shigematsu,* Natsuko KaYakiRI, Satoshi Okada, and Hirokazu Tanaka \\ Exploratory Research Laboratories, Fujisawa Pharmaceutical Co., Ltd., 5-2-3 Tokodai, Tsukuba, Ibaraki 300-26, \\ Japan. Received June 24, 1996; accepted September 20, 1996
}

Total synthesis of the cyclic peptide lactone WS9326A, a potent tachykinin antagonist isolated from Streptomyces violaceoniger strain 9326, has been achieved via Cbz-Thr(Boc-allo-Thr-Asn-Ser(Bzl))-(E)AMeTyr-Leu-DPhe-OTce, which was cyclized (Phe and allo-Thr) using an active ester method with $N$-hydroxysuccinimide. Finally the unique $N$-acyl group, the 2-(1(Z)-pentenyl)cinnamoyl moiety, was introduced onto the amino group in the Thr unit. The key step of the synthesis involves the preparation of the $E$-isomer of the dehydro- $N$-methyltyrosine $(\Delta \mathrm{MeTyr})$ unit. The debenzoxylation reaction of the threo- and erythro-isomers of $\beta$-benzoxy- $N$-methyltyrosine derivatives gave exclusively the $Z$-isomer of $\mathrm{Cbz}-\mathrm{Thr}-\triangle \mathrm{MeTyr}(\mathrm{MOM})-\mathrm{OMe}$, which was then converted to the desired $E$-isomer by photochemical isomerization of Cbz-Thr(TBDMS)-(Z)AMeTyr(MOM)-Leu-D-Phe-OTce at a later step.

Key words tachykinin antagonist; photochemical isomerization; cyclic peptide lactone

The cyclic peptide lactone WS9326A (1) (Fig. 1), isolated from Streptomyces violaceoniger strain 9326, shows strong antagonistic activity to substance $\mathrm{P}$ and neurokinin $\mathrm{A}$ receptors. ${ }^{2)}$ Compound 1 consists of L-Thr, $(E)$-dehydro$N$-methyltyrosine ((E) $\Delta \mathrm{MeTyr})$, L-Leu, D-Phe, L-allo-Thr, L-Asn, L-Ser, and the unique $N$-acyl group, 2-(1(Z)pentenyl)cinnamic acid. Structural requirements for activity have been partially elucidated during structural assignment; namely, the dehydroamino acid and $N$-acyl group are essential for activity. ${ }^{3)}$ A tetrahydro acyl group derivative of $\mathbf{1}$ is ten times more active than the natural

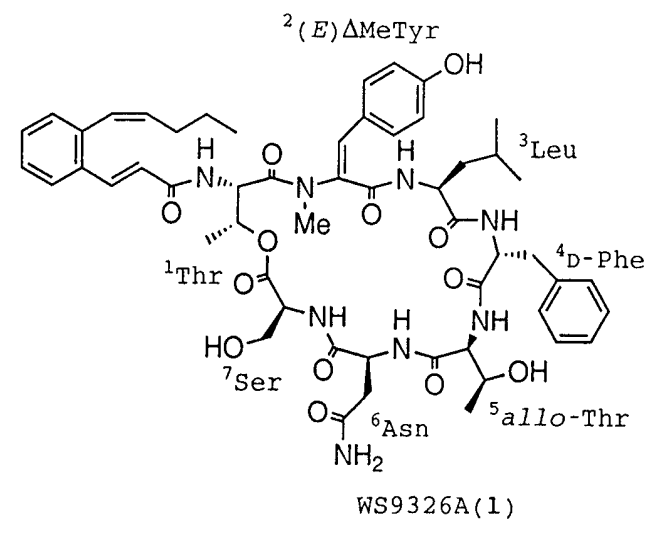

Fig. 1 compound (1) at neurokinin receptors (NK1, NK2). ${ }^{2)}$ This derivative (code No. FK224) is currently in phase II clinical trials as a potential antiasthmatic agent. We describe here the first total synthesis of 1 via a cyclic peptide lactone (21) which has a free amino group in the Thr unit, allowing synthesis of various $N$-acyl derivatives, and we also report the synthesis of $\mathrm{N}$-acyl derivatives using the intermediate 21, as well as some structure-activity relationships.

\section{Results and Discussion}

Our retrosynthetic analysis is shown in Chart 1 . The greatest challenge involved the preparation of the required $E$-isomer of the dehydro- $N$-methyltyrosine $(\Delta \mathrm{MeTyr})$ unit. ${ }^{4}$ Synthesis of the $\beta$-hydroxy- $N$-methyltyrosine derivative 9 was started from commercially available 4-hydroxy benzaldehyde. After protection of the hydroxy group with methoxymethyl (MOM), ${ }^{5}$ conjugation with Gly gave a $c a .1: 1$ mixture of threo- and erythro-isomers of the $\beta$-hydroxytyrosine unit. The diastereomeric mixture (3) was then $N$-methylated with dimethyl sulfate, followed by protection of the amino group with 2-nitrophenylsulfenyl (Nps) chloride ${ }^{6)}$ and the carboxyl group as the methyl ester to give 6. The threo- and erythro-isomers of 6 were separated by silica gel column chromatography using $\mathrm{CHCl}_{3}$ as a solvent to give $\mathbf{6 a}$ and $\mathbf{6 b}$ (Chart 2).

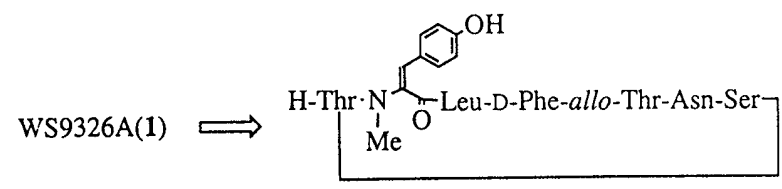

21

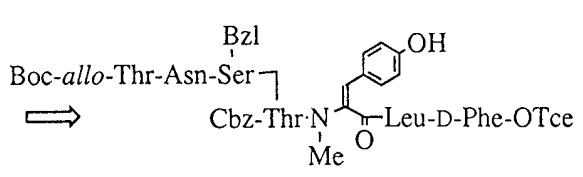

18

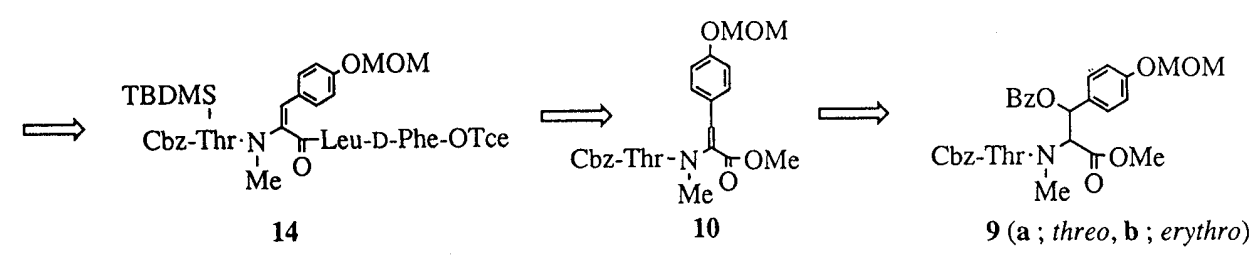

Chart 1. Retrosynthetic Route for WS9326A (1) 


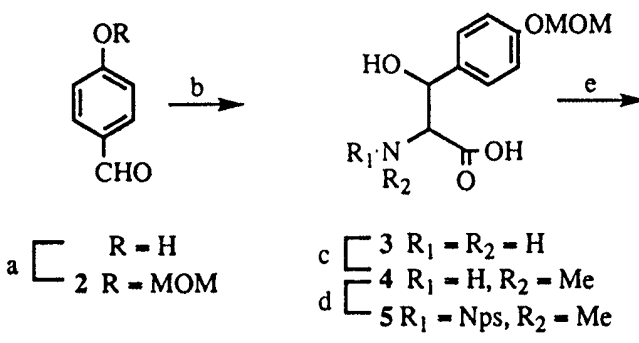<smiles>COC(=O)C(C(O)c1ccc(OC)cc1)[N+]([N])=O</smiles>

6(a; threo, $\mathbf{b} ;$ erythro $)$

(a) $\mathrm{CH}_{3} \mathrm{OCH}{ }_{2} \mathrm{Cl}$, TEA, THF, rt, lh; (b) $\mathrm{Gly}, \mathrm{KOH}, \mathrm{EtOH}, \mathrm{rt}, 19 \mathrm{~h}$; (c) $(\mathrm{MeO})_{2} \mathrm{SO}_{2}, 1 \mathrm{~N} \mathrm{NaOH}, 90^{\circ} \mathrm{C}, 20 \mathrm{~min}$; (d) $\mathrm{NpsCl}, \mathrm{BSA}, \mathrm{CH}_{2} \mathrm{Cl}_{2}, 0^{\circ} \mathrm{C}, 2 \mathrm{~h}$; (e) $\mathrm{CH}_{2} \mathrm{~N}_{2} /$ ether.

Chart 2<smiles>COc1ccc(C(O)C(C(C)=O)[N+]([N])=O)cc1</smiles>

6(a; threo, b; erythro )

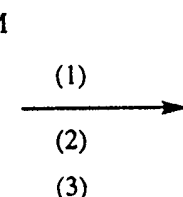

(3)<smiles>COc1ccc(C2OC(=O)N(C)C2C(=O)O)cc1</smiles>

6'(a; threo, b; erythro)

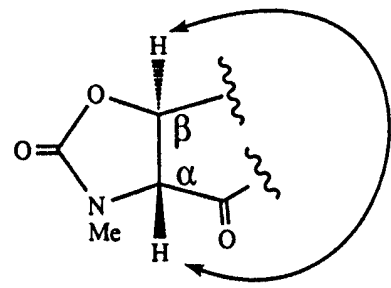

$J_{\text {trans }}=5 \mathrm{~Hz}($ threo $)$

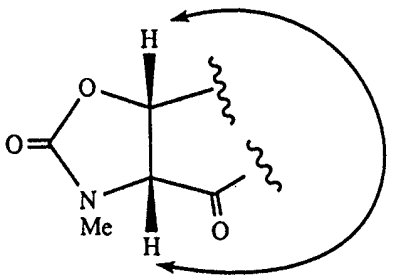

$J_{c i s}=9 \mathrm{~Hz}$ (erythro)

(3) $\mathrm{NaOH}, 50^{\circ} \mathrm{C}, 6 \mathrm{~h}$.

Fig. 2. Coupling Constants of Oxazolidone Derivative

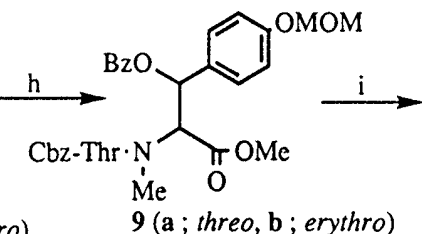

9 (a; threo, b ; erythro)

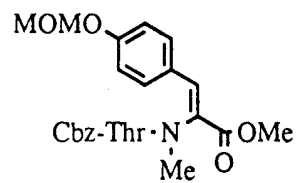

10

$\mathrm{g}\left[\begin{array}{l}\mathbf{7} \mathrm{R}_{1}=\mathrm{Nps}, \mathrm{R}_{2}=\mathrm{Bz}(\mathbf{a} ; \text { threo,b; erythro }) \\ \mathbf{8} \mathrm{R}_{1}=\mathrm{H}, \mathrm{R}_{2}=\mathrm{Bz}(\mathbf{a} ; \text { threo, } \mathbf{b} ; \text { erythro })\end{array}\right.$

(f) $\mathrm{BzCl}, \mathrm{DMAP}, \mathrm{TEA}, \mathrm{CH}_{2} \mathrm{Cl}_{2}, \mathrm{n}, 2 \mathrm{~d}$; (g) $\mathrm{PhSH}, \mathrm{TFA}, \mathrm{CH}_{2} \mathrm{Cl}_{2}, 0^{\circ} \mathrm{C}, 30 \mathrm{~min}$;

(h) $\mathrm{Cbz}-\mathrm{Thr}-\mathrm{OH}, \mathrm{EEDQ}, \mathrm{CH}_{2} \mathrm{Cl}_{2}, \mathrm{rt}, 20 \mathrm{~min}$; (i) DBU, toluene, $\mathrm{rt}, 30 \mathrm{~min}$.

Chart 4

In order to verify the stereochemical integrity of $6 \mathbf{a}$ and $\mathbf{6 b}$, the Nps group of both compounds was removed and the deprotected compounds were treated with benzyloxycarbonyl chloride, followed by cyclization to the corresponding 2-oxazolidone derivatives $\left(\mathbf{6}^{\prime} \mathbf{a}, \mathbf{6}^{\prime} \mathbf{b}\right)$ (Chart 3$)$. In the ${ }^{1} \mathrm{H}$-NMR spectra of these two compounds, the vicinal coupling constants between the $\mathrm{C}_{\alpha}-\mathrm{H}$ and $\mathrm{C}_{\beta}-\mathrm{H}$ protons verified $\mathbf{6}^{\prime} \mathbf{a}$ as the threo $\left(J_{\alpha-\beta}=5 \mathrm{~Hz}\right)$ and $\mathbf{6}^{\prime} \mathbf{b}$ as the erythro $\left(J_{\alpha-\beta}=9 \mathrm{~Hz}\right)$ isomer (Fig. 2). ${ }^{7)}$

The hydroxy group of each of $\mathbf{6 a}$ and $\mathbf{6 b}$ was protected with benzoyl chloride to afford $\mathbf{7 a}$ and $\mathbf{7 b}$. Removal of the $\mathrm{Nps}$ group of $\mathbf{7 a}$ and $\mathbf{7 b}$, followed by coupling with $\mathrm{Cbz}-\mathrm{Thr}-\mathrm{OH}$ using 2-ethoxy- $N$-ethoxycarbonyl-1,2-dihydroquinoline (EEDQ) ${ }^{8)}$ as a condensing reagent afforded threo (9a) and erythro (9b) isomers (Chart 4).

Both intermediates, 9a (threo) and 9b (erythro), gave exclusively the $Z$-isomer (10) as the elimination product upon treatment with 1,8-diazabicyclo[5.4.0]undec-7-ene (DBU). The stereochemistry of the double bond in the dehydro peptide (10) was established by analysis of the nuclear Overhauser effect (NOE) difference spectra. ${ }^{9)}$ The $\triangle$ MeTyr unit of $\mathbf{1 0}$ showed NOE between the $N$-methyl protons at $\delta 3.14$ and the aromatic protons at $\delta 7.46\left(2^{\prime}, 6^{\prime}\right)$, indicating that $\Delta \mathrm{MeTyr}$ had the $Z$ configuration as shown.

The desired $E$-isomer was obtained by photochemical isomerization of the tetrapeptide $13 .^{10)}$ Protection of the hydroxyl group of $\mathbf{1 0}$ with tert-butyldimethylsilyl chloride $(\mathrm{TBDMSCl})^{11)}$ followed by removal of the methyl ester gave 12. Synthesis of 13 was achieved by coupling 12 with H-Leu-D-Phe-OTce (22) ${ }^{12)}$ using EEDQ. Compound 13 in toluene-acetone $(10: 1)$ solution was irradiated with a high-pressure $\mathrm{Hg}$ lamp $(100 \mathrm{~W})$ for $1.5 \mathrm{~h}$ at $0^{\circ} \mathrm{C}$ to afford a 2:1 mixture of the starting material (13) and the $E$-isomer 14 (Chart 5). It was known that the $(E) \Delta$-amino acid ester is unstable to acid and base, and is easily converted to the $(Z) \Delta$-amino acid. ${ }^{13)}$ The results might be related to the stability of the products, i.e., a longer peptide chain at the $\mathrm{C}$-terminal of $\triangle \mathrm{MeTyr}(\mathbf{1 3})$ would impart a more stable conformation for the $E$-orientation (14) as compared with the methyl ester (10).

The stereochemistry of the double bond in compounds 13 and 14 was also established based on NOE difference 


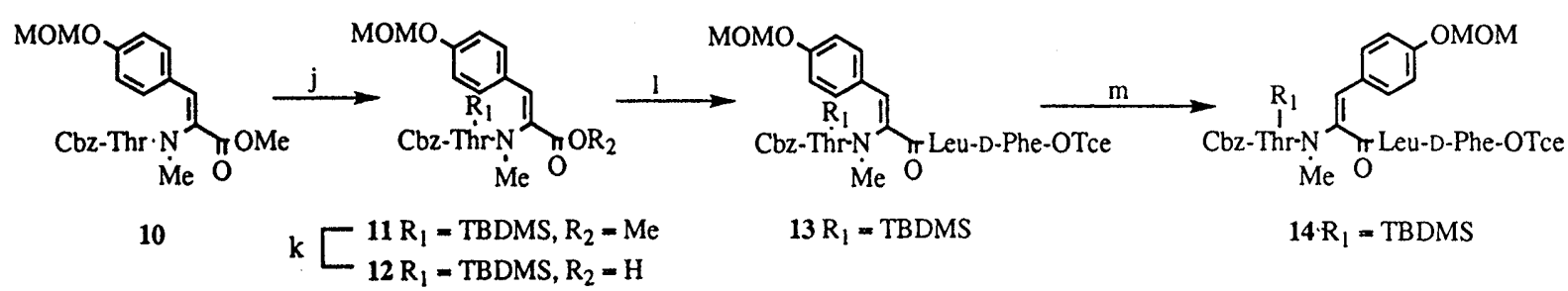

(j) TBDMSCl, imidazole, DMF, $\mathrm{nt}, 16 \mathrm{~h}$; (k) IN NaOH, $30^{\circ} \mathrm{C}, 2 \mathrm{~d}$; (l) H-Leu-D-Phe-OTce (22), EEDQ, $\mathrm{CH}_{2} \mathrm{Cl}_{2}, \mathrm{rt}, 15 \mathrm{~h}$; (m) toluene : acetone $-10: 1, \mathrm{hv}(100 \mathrm{~W}), 0^{\circ} \mathrm{C}, 1.5 \mathrm{~h}$.

Chart 5

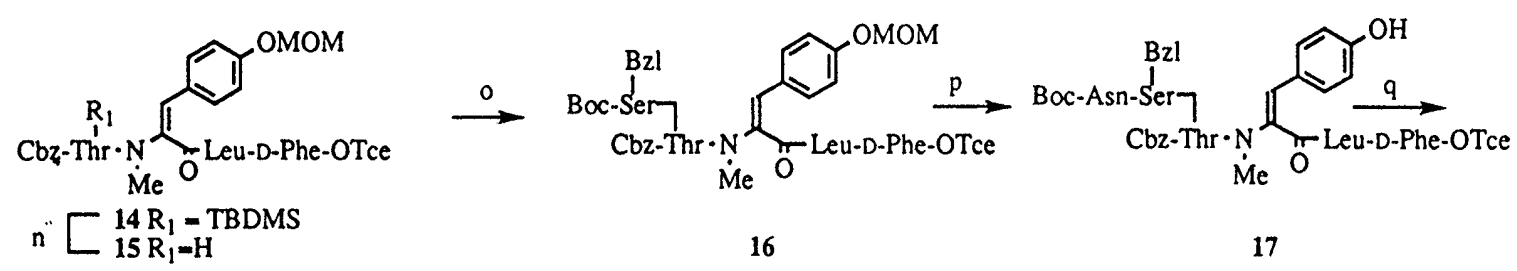

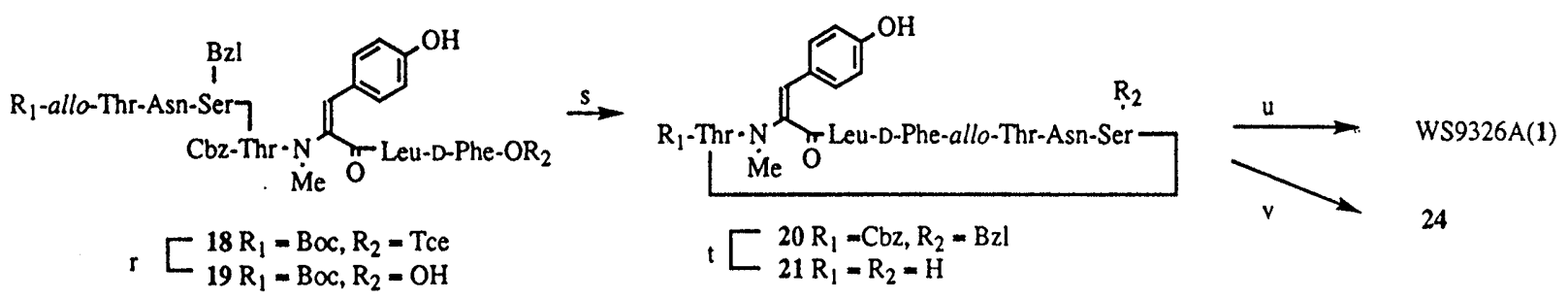

(n) $67 \% \mathrm{AcOH}, 25^{\circ} \mathrm{C}, 28 \mathrm{~h}$; (o) Boc-Ser(Bzl)-OH, EDC.HCl, DMAP, $\mathrm{CH}_{2} \mathrm{Cl}_{2}, \mathrm{rt}, 12 \mathrm{~h}$; (p) $4 \mathrm{~N} \mathrm{HCl} /$ dioxane, $\mathrm{rt}, 30 \mathrm{~min}$, then Boc-Asn-OH, TEA, HOBT, EDC. $\mathrm{HCl}, \mathrm{CH}_{2} \mathrm{Cl}_{2}, \mathrm{r}, \mathrm{l} \mathrm{h}$; (q) $4 \mathrm{~N} \mathrm{HCl} /$ dioxane, $\mathrm{nt}, 30 \mathrm{~min}$, then Boc-allo-Thr-OH, TEA, HOBT, EDC $\cdot \mathrm{HCl}, \mathrm{CH} \cdot \mathrm{Cl}, \mathrm{rt}, 8 \mathrm{~h}$; (r) $90 \% \mathrm{AcOH}, \mathrm{Zn}, \mathrm{rt}, 9 \mathrm{~h}$; (s)l) HONSu, EDC. $\left.\mathrm{HCl}, \mathrm{CH}_{2} \mathrm{Cl}_{2}, \mathrm{r}, 15 \mathrm{~h} ; 2\right)$ TFA, $\mathrm{r}, 30 \mathrm{~min}$, then DMF pyridine, $\mathrm{tt}, 16 \mathrm{~h}$;

(t) HF-pyridine, $\mathrm{n}$, Ih; (u) 2-(1(7)-pentenyl)cinnamoyl chloride (23), $\mathrm{CH}_{2} \mathrm{Cl}_{2}, \mathrm{BSA}, \mathrm{DMF}, \mathrm{r}, 1 \mathrm{~h}$;; (v) stearoyl chloride, pyridine, $\mathrm{tt}$, $\mathrm{th}$.

\section{Chart 6}

spectra as $Z$ and $E$, respectively. ${ }^{14)}$ The results were consistent with the UV spectra of these compounds. The intensity of the UV absorption maximum of $\mathbf{1 3}(305 \mathrm{~nm}$, $\varepsilon$ 18500) was larger than that of $\mathbf{1 4}(284 \mathrm{~nm}, \varepsilon 8865)$, thereby confirming $Z(\mathbf{1 3})$ and $E$ (14) configurations in accordance with the result observed for trans-cinnamic acid. ${ }^{15)}$

The $E$-isomer 14 was purified by silica gel column chromatography ( $n$-hexane-EtOAc, $2: 1)$ and allowed to react, after removal of the TBDMS protecting group, with Boc-Ser(Bzl)-OH using EDC hydrochloride (EDC $\cdot \mathrm{HCl}) /$ $\mathrm{N}, \mathrm{N}$-dimethylamino pyridine (DMAP) to form the ester bond with the hydroxyl group in the Thr unit. Two successive peptide chain elongation reactions with BocAsn-OH and Boc-allo-Thr-OH using EDC/HOBT gave a linear protected peptide (18) which contained all the required amino acid units. Compound $\mathbf{1 8}$ was allowed to react, after removal of the trichloroethyl group on D-Phe, with $\mathrm{HONSu}$ using $\mathrm{EDC} \cdot \mathrm{HCl}$ to give an activated ester. The Boc group in the allo-Thr unit of the active ester was deprotected with TFA, and cyclization was achieved by a high dilution method ${ }^{16)}$ in pyridine to give cyclic peptide 20 in $40 \%$ overall yield (from the free acid). The Cbz and Bzl protecting groups of $\mathbf{2 0}$ were removed simultaneously with HF-pyridine to afford the free cyclic peptide lactone 21.

The preparation of the $N$-acyl group has been reported previously, ${ }^{3)}$ and the route employed was followed in the present synthesis to afford 2-(1(Z)-pentenyl)cinnamoyl chloride (23). The acid chloride was coupled with 21 in the presence of $\mathrm{N}, \mathrm{O}$-bis(trimethylsilyl)acetamide (BSA) and DMAP, and the product, which showed the same $R f$ value $\left(0.59, \mathrm{CHCl}_{3}-\mathrm{MeOH}-\mathrm{H}_{2} \mathrm{O}, 65: 25: 4\right)$ as natural $\mathbf{1}$, was purified by preparative TLC (Chart 6). Synthetic 1 was identical, in terms of ${ }^{1} \mathrm{H}-\mathrm{NMR}, \mathrm{FAB}$ mass spectra, IR and analytical RP-HPLC behavior (Fig. 3), with natural 1.

The yield of the $N$-acyl group coupling reaction was very low $(2.7 \%)$. In order to ascertain the reason, we synthesized a derivative using intermediate $\mathbf{2 1}$. In the case of stearoyl as an $\mathrm{N}$-acyl group, compound $\mathbf{2 4}$ was obtained in $13.8 \%$ yield. Thus, the former result was probably due to the structural complexity of the acyl group.

Synthetic 1 inhibits the binding of $\left[{ }^{3} \mathrm{H}\right]$ substance $P$ to a guinea pig lung membrane preparation with an $\mathrm{IC}_{50}$ value of $3.5 \times 10^{-6} \mathrm{M}$, which is the same value as that of the natural product. On the other hand, compounds 21 and 24 showed values of $>30 \times 10^{-6} \mathrm{M}$ and $>36 \times 10^{-6} \mathrm{M}$, respectively. These results indicate that the structure of the $N$-acyl group is important for the activity.

In conclusion, a stereoselective and convergent synthesis of WS9326A has been achieved. The synthetic route established in the present study should be useful for providing a variety of $N$-acyl derivatives to evaluate structure-activity relationships, in an effort to discover more potent derivatives. 

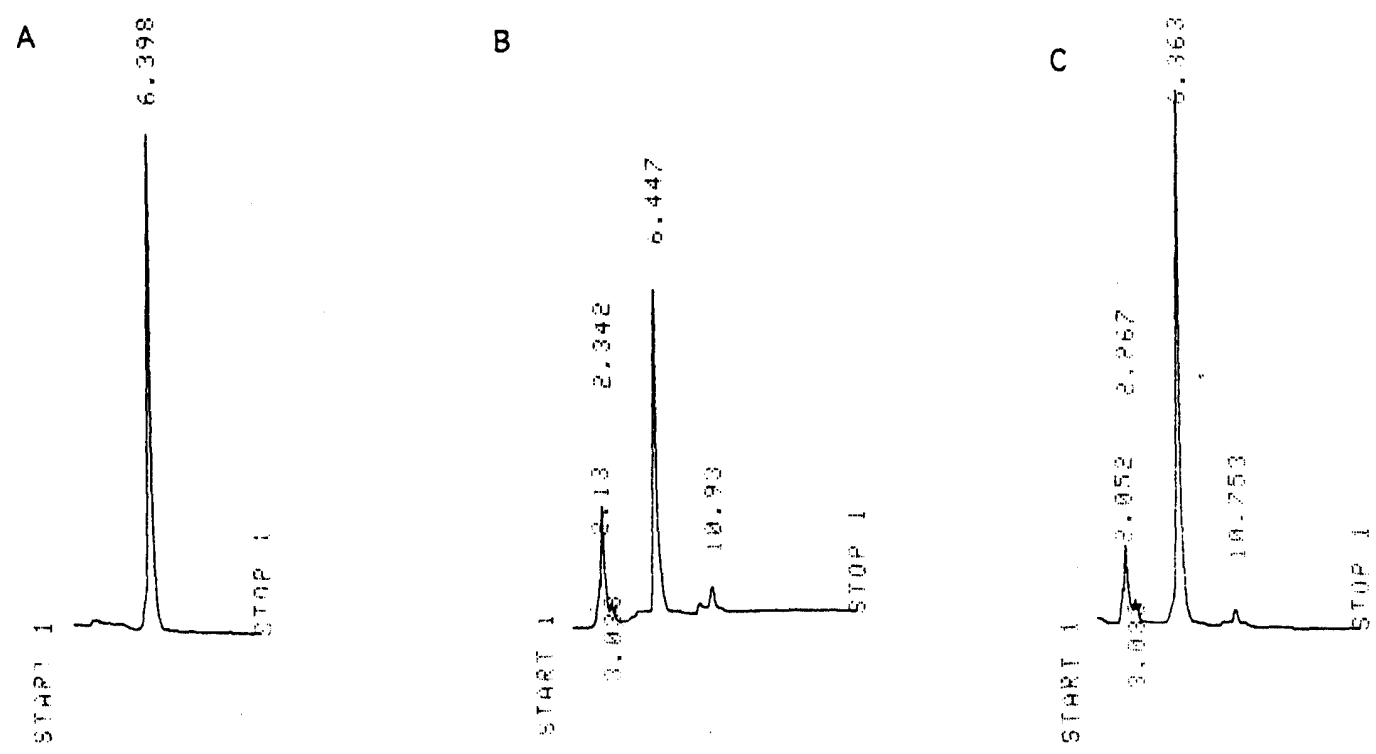

Fig. 3. HPLC Profiles of Natural and Synthetic WS9326A

RP-HPLC conditions: column YMC AM-303 (250 mm $\times 4.6 \mathrm{~mm}$ i.d.); eluate, $\mathrm{MeOH}: \mathrm{H}_{2} \mathrm{O}(80: 20)$; flow rate, $1 \mathrm{ml} / \mathrm{min}$; detection, UV $210 \mathrm{~nm}$. A) Natural WS9326A, B) synthetic WS9326A, C) mixture of natural and synthetic WS9326A.

\section{Experimental}

Melting points (mp) were taken using a Yanagimoto micro melting point apparatus and are uncorrected. IR spectra were recorded on a JASCO A-102 or a Perkin-Elmer 16PC FT-IR spectrophotometer. UV spectra were measured on a Hitachi 220A spectrophotometer. Optical rotations were determined with a JASCO DIP-140 polarimeter. ${ }^{1} \mathrm{H}$ - and ${ }^{13} \mathrm{C}$-NMR spectra were measured on a Bruker AM200 or AM400WB NMR spectrometer. Mass spectra were measured on a VG ZAB-SE mass spectrometer. Analytical TLC was done on $2.0 \times 6.5 \mathrm{~cm}$ precoated TLC plates (Silica gel $60 \mathrm{~F}_{254}$, layer thickness $0.25 \mathrm{~mm}$ ) manufactured by $\mathrm{E}$. Merck. Column chromatography was carried out with E. Merck Silica gel 60 (70-230 mesh ASTM). Acid hydrolysis of samples was conducted with $6 \mathrm{~N} \mathrm{HCl}$ at $110^{\circ} \mathrm{C}$ for $18 \mathrm{~h}$ in evacuated sealed tubes and amino acid analysis was performed on a JEOL JLC-500 amino acid analyzer system. $N^{\alpha}$-Boc-amino acids and $N^{\alpha}$-Cbz-amino acids were purchased from Peptide Institute, Inc., Osaka, Japan.

4-Methoxymethoxybenzaldehyde (2) Chloromethyl methyl ether $(33 \mathrm{ml})$ was added to a solution of 4-hydroxybenzaldehyde $(40.2 \mathrm{~g})$ in tetrahydrofuran (THF) $(400 \mathrm{ml})$ and $\mathrm{Et}_{3} \mathrm{~N}(80 \mathrm{ml})$ and the solution was stirred for $1 \mathrm{~h}$ at room temperature. The solvent was evaporated, and the residue was dissolved in ether. This solution was washed with $1 \mathrm{~N}$ $\mathrm{NaOH}$, dried $\left(\mathrm{MgSO}_{4}\right)$, and evaporated. The residue was distilled under vacuum $\left(84-85^{\circ} \mathrm{C} / 0.6 \mathrm{mmHg}\right)$ to give 2 as a pale yellow oil $(48.5 \mathrm{~g}$, $88.7 \%) .{ }^{1} \mathrm{H}-\mathrm{NMR}\left(\mathrm{CDCl}_{3}\right) \delta: 3.50(3 \mathrm{H}, \mathrm{s}), 5.26(2 \mathrm{H}, \mathrm{s}), 7.14(2 \mathrm{H}, \mathrm{d}$, $J=12 \mathrm{~Hz}), 7.83(2 \mathrm{H}, \mathrm{d}, J=12 \mathrm{~Hz}), 9.90(1 \mathrm{H}, \mathrm{s})$.

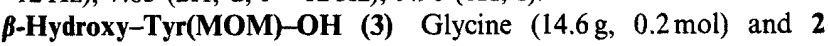
$(48.5 \mathrm{~g}, 0.29 \mathrm{~mol})$ were added to a suspension of $\mathrm{KOH}(26.8 \mathrm{~g}, 0.4 \mathrm{~mol})$ in EtOH $(500 \mathrm{ml})$ at room temperature, and the reaction mixture was stirred for $19 \mathrm{~h}$. The solvent was evaporated, then the residue was dissolved in $\mathrm{H}_{2} \mathrm{O}$ and acidified with $\mathrm{HCl}$. The solution was washed with EtOAc and adjusted to $\mathrm{pH} 6$ with $\mathrm{NaHCO}_{3}$. A white solid precipitated and was collected by filtration to give $3(9.2 \mathrm{~g}, 20 \%)$. The filtrate was put on a column of Diaion HP-20 (Mitsubishi Kasei Co.), which was washed with $\mathrm{H}_{2} \mathrm{O}$, and eluted with $90 \% \mathrm{MeOH}$. The eluate was evaporated, and the residual solid was rinsed with acetone to give additional 3 as a solid $(12.0 \mathrm{~g}, 25.5 \%)$. mp $164-166^{\circ} \mathrm{C}$. Rf 0.57 $\left(n-\mathrm{BuOH}-\mathrm{AcOH}-\mathrm{H}_{2} \mathrm{O}(5: 2: 3)\right)$. IR $(\mathrm{KBr}) \mathrm{cm}^{-1}: 1610,1510,1400$. ${ }^{1} \mathrm{H}-\mathrm{NMR}\left(\mathrm{D}_{2} \mathrm{O}\right)$ a mixture of diastereomers $(1: 1) \delta: 3.51(6 \mathrm{H}, \mathrm{s}), 3.90$ $(1 \mathrm{H}, \mathrm{d}, J=4.6 \mathrm{~Hz}), 4.08(1 \mathrm{H}, \mathrm{d}, J=4.2 \mathrm{~Hz}), 5.27(1 \mathrm{H}, \mathrm{d}, J=4.6 \mathrm{~Hz})$, $5.29(4 \mathrm{H}, \mathrm{s}), 5.35(1 \mathrm{H}, \mathrm{d}, J=4.2 \mathrm{~Hz}), 7.13(2 \mathrm{H}, \mathrm{d}, J=8.5 \mathrm{~Hz}), 7.16(2 \mathrm{H}$, $\mathrm{d}, J=8.5 \mathrm{~Hz}), 7.38(2 \mathrm{H}, \mathrm{d}, J=8.5 \mathrm{~Hz}), 7.44(2 \mathrm{H}, \mathrm{d}, J=8.5 \mathrm{~Hz})$. FAB-MS $m / z 242(\mathrm{M}+\mathrm{H})^{+}$. Anal. Calcd for $\mathrm{C}_{11} \mathrm{H}_{15} \mathrm{NO}_{5} \cdot 1 / 2 \mathrm{H}_{2} \mathrm{O}: \mathrm{C}, 52.80 ; \mathrm{H}$, $6.44 ; \mathrm{N}, 5.60$. Found: C, 52.88; H, 6.46; N, 5.60.

$\beta$-Hydroxy-MeTyr(MOM)-OH (4) A solution of $3(21.0 \mathrm{~g}, 87 \mathrm{mmol})$ in $1 \mathrm{~N} \mathrm{NaOH}(250 \mathrm{ml})$ was treated with $(\mathrm{MeO})_{2} \mathrm{SO}_{4}(16.5 \mathrm{~g}, 130 \mathrm{mmol})$. The mixture was stirred for $20 \mathrm{~min}$ at $90^{\circ} \mathrm{C}$, then acidified with dilute
$\mathrm{HCl}$ at $0^{\circ} \mathrm{C}$, washed with $\mathrm{Et}_{2} \mathrm{O}$, adjusted to $\mathrm{pH} 6.0$ with $1 \mathrm{~N} \mathrm{NaOH}$ and concentrated. The precipitate was collected by filtration to give $4(5.2 \mathrm{~g}$, $23 \%$ ). Additional 4 was obtained from the filtrate in the same manner as described for $3(6.0 \mathrm{~g}, 27 \%)$. mp $177-178^{\circ} \mathrm{C}$. Rf $0.54(n-\mathrm{BuOH}-$ AcOH- $\left.\mathrm{H}_{2} \mathrm{O}(5: 2: 3)\right)$. IR (KBr) cm ${ }^{-1}: 3100,1600,1375,1350 .{ }^{1} \mathrm{H}-\mathrm{NMR}$ $\left(\mathrm{D}_{2} \mathrm{O}\right)$ mixture of diastereomers $(1: 1) \delta: 2.68(3 \mathrm{H}, \mathrm{s}), 3.03(3 \mathrm{H}, \mathrm{s}), 3.50$ $(6 \mathrm{H}, \mathrm{s}), 3.75(1 \mathrm{H}, \mathrm{d}, J=7.4 \mathrm{~Hz}), 3.88(1 \mathrm{H}, \mathrm{d}, J=10 \mathrm{~Hz}), 5.01(1 \mathrm{H}, \mathrm{d}$, $J=7.4 \mathrm{~Hz}), 5.02(1 \mathrm{H}, \mathrm{d}, J=10 \mathrm{~Hz}), 5.29(4 \mathrm{H}, \mathrm{s}), 7.12(2 \mathrm{H}, \mathrm{d}, J=8.5 \mathrm{~Hz})$, $7.14(2 \mathrm{H}, \mathrm{d}, J=8.5 \mathrm{~Hz}), 7.42(4 \mathrm{H}, \mathrm{d}, J=8.5 \mathrm{~Hz})$. FAB-MS $m / z: 256$ $(\mathrm{M}+\mathrm{H})^{+}$. Anal. Calcd for $\mathrm{C}_{12} \mathrm{H}_{17} \mathrm{NO}_{5}: \mathrm{C}, 56.46 ; \mathrm{H}, 6.71 ; \mathrm{N}, 5.49$. Found: C, 56.24; H, 6.88; N, 5.51.

$\boldsymbol{\beta}$-Hydroxy- $\boldsymbol{N}^{\alpha}$-Nps-MeTyr(MOM)-OH (5) A solution of $\mathrm{NpsCl}$ (11.2 $\mathrm{g}, 59 \mathrm{mmol})$ in $\mathrm{CH}_{2} \mathrm{Cl}_{2}(50 \mathrm{ml})$ was added to a solution of $4(15.1 \mathrm{~g}$, $59 \mathrm{mmol})$ and BSA $(25 \mathrm{ml}, 0.1 \mathrm{~mol})$ in $\mathrm{CH}_{2} \mathrm{Cl}_{2}(150 \mathrm{ml})$, and the mixture was stirred for $2 \mathrm{~h}$ at $0^{\circ} \mathrm{C}$. BSA $(10 \mathrm{ml}, 40 \mathrm{mmol})$ and $\mathrm{NpsCl}(5.6 \mathrm{~g}$, $30 \mathrm{mmol}$ ) were added, and the whole was stirred for $3 \mathrm{~h}$ at room temperature, then $1 \mathrm{~N} \mathrm{NaOH}(200 \mathrm{ml})$ was added. The organic layer was washed with $\mathrm{H}_{2} \mathrm{O}(300 \mathrm{ml})$ and the aqueous solutions were combined, acidified with dilute $\mathrm{HCl}$, and extracted with EtOAc $(300 \mathrm{ml})$. The organic solution was washed with $\mathrm{H}_{2} \mathrm{O}(100 \mathrm{ml} \times 3)$, dried $\left(\mathrm{MgSO}_{4}\right)$, and evaporated to give 5 as a solid $(20.5 \mathrm{~g}, 85 \%) . \mathrm{mp} 59-60^{\circ} \mathrm{C} . R f 0.34$, $0.48\left(\mathrm{CHCl}_{3}-\mathrm{MeOH}-\mathrm{AcOH}(10: 1: 0.1)\right)$. IR (KBr) cm${ }^{-1}: 3400,1700$, 1495, 1300. FAB-MS $m / z: 409(\mathrm{M}+\mathrm{H})^{+}$. HR-FAB-MS $m / z$ : Calcd for $\mathrm{C}_{18} \mathrm{H}_{21} \mathrm{~N}_{2} \mathrm{O}_{7} \mathrm{~S}(\mathrm{M}+\mathrm{H})^{+}:$409.1069. Found: 409.1083.

$\beta$-Hydroxy- $N^{\alpha}$-Nps-MeTyr(MOM)-OMe (6) A solution of $5(20.0 \mathrm{~g}$ $49 \mathrm{mmol})$ in EtOAc $(100 \mathrm{ml})$ was treated with freshly prepared $\mathrm{CH}_{2} \mathrm{~N}_{2}$ in $\mathrm{Et}_{2} \mathrm{O}(80 \mathrm{ml})$. The mixture was stirred for $10 \mathrm{~min}$, then evaporated. The residue was purified on a silica gel column $\left(500 \mathrm{~g}, \mathrm{CHCl}_{3}\right)$ to give 6 as an oil. (threo isomer (6a): $8.82 \mathrm{~g} \mathrm{(42.6 \% ),} \mathrm{erythro} \mathrm{isomer} \mathrm{(6b):} 6.63 \mathrm{~g}$ $(32.1 \%))$.

threo Isomer (6a): Oil. Rf 0.40 (EtOAc- $n$-hexane (1:1)). IR (film) $\mathrm{cm}^{-1}: 3500,2950,1735,1510 .{ }^{1} \mathrm{H}-\mathrm{NMR}\left(\mathrm{CDCl}_{3}\right) \delta: 3.15(3 \mathrm{H}, \mathrm{s}), 3.50$ $(3 \mathrm{H}, \mathrm{s}), 3.63(3 \mathrm{H}, \mathrm{brs}), 3.94(1 \mathrm{H}, \mathrm{d}, J=8 \mathrm{~Hz}), 5.18(2 \mathrm{H}, \mathrm{s}), 5.22(1 \mathrm{H}$, $\mathrm{m}), 7.02(2 \mathrm{H}, \mathrm{d}, J=8.5 \mathrm{~Hz}), 7.30(2 \mathrm{H}, \mathrm{d}, J=8.5 \mathrm{~Hz}), 7.15-7.70(4 \mathrm{H}$, $\mathrm{m}), 8.27(1 \mathrm{H}, \mathrm{d}, J=8 \mathrm{~Hz})$. FAB-MS $m / z: 423(\mathrm{M}+\mathrm{H})^{+}$. HR-FAB-MS Calcd for $\mathrm{C}_{19} \mathrm{H}_{23} \mathrm{~N}_{2} \mathrm{O}_{7} \mathrm{~S} 423.1226(\mathrm{M}+\mathrm{H})^{+}$. Found 423.1233.

erythro Isomer (6b): Oil. Rf 0.31 (EtOAc- $n$-hexane $(1: 1)$ ). IR (film) $\mathrm{cm}^{-1}: 3500,2950,1735,1510 .{ }^{1} \mathrm{H}-\mathrm{NMR}\left(\mathrm{CDCl}_{3}\right)$ (three conformers $(4: 2: 1)$ existed in the solvent) major conformer $\delta: 2.72(3 \mathrm{H}, \mathrm{s}), 3.50$ $(3 \mathrm{H}, \mathrm{s}), 3.88(3 \mathrm{H}, \mathrm{s}), 3.90(1 \mathrm{H}, \mathrm{m}), 5.10(1 \mathrm{H}, \mathrm{m}), 5.22(2 \mathrm{H}, \mathrm{s}), 7.05-7.50$ $(8 \mathrm{H}, \mathrm{m}), 8.20(1 \mathrm{H}, \mathrm{m})$. FAB-MS $m / z 423(\mathrm{M}+\mathrm{H})^{+}$. HR-FAB-MS $m / z$ : Calcd for $\mathrm{C}_{19} \mathrm{H}_{23} \mathrm{~N}_{2} \mathrm{O}_{7} \mathrm{~S}:(\mathrm{M}+\mathrm{H})^{+}: 423.1226$. Found: 423.1235 .

$\beta$-Benzoxy- $N^{\alpha}-\mathrm{Nps}-\mathrm{MeTyr}(\mathrm{MOM})-\mathrm{OMe}$ (threo) (7a) $\mathrm{Et}_{3} \mathrm{~N}(6.3 \mathrm{~g}$, $63 \mathrm{mmol})$, DMAP $(1.53 \mathrm{~g}, 12.5 \mathrm{mmol})$, and benzoyl chloride $(8.8 \mathrm{~g}, 63$ $\mathrm{mmol})$ were added to a solution of $6 \mathrm{a}(5.29 \mathrm{~g}, 12.5 \mathrm{mmol})$ in $\mathrm{CH}_{2} \mathrm{Cl}_{2}$ $(50 \mathrm{ml})$. The solution was stirred for $2 \mathrm{~d}$ at room temperature, then 
3-dimethylaminopropylamine $(19 \mathrm{~g}, 0.19 \mathrm{~mol})$ was added. The mixture was concentrated and the residue was dissolved in EtOAc $(30 \mathrm{ml})$. This solution was washed with dilute $\mathrm{HCl}, \mathrm{NaHCO}_{3}$ and $\mathrm{H}_{2} \mathrm{O}$, then evaporated, and the residue was purified by silica gel column chromatography $(200 \mathrm{~g}, n$-hexane-EtOAc $(5: 2))$ to give $7 \mathbf{a}$ as a solid $(5.40 \mathrm{~g}$, $81.9 \%$ ). mp $114-115^{\circ} \mathrm{C} . R f 0.26(\mathrm{AcOEt}-n$-hexane $(1: 2))$. IR $\left(\mathrm{CHCl}_{3}\right)$ $\mathrm{cm}^{-1}: 2950,1740,1515$. FAB-MS $m / z: 527(\mathrm{M}+\mathrm{H})^{+}$. HR-FABMS $m / z$ : Calcd for $\mathrm{C}_{26} \mathrm{H}_{27} \mathrm{~N}_{2} \mathrm{O}_{8} \mathrm{~S}(\mathrm{M}+\mathrm{H})^{+}: 527.1488$. Found: 527.1520 .

$\boldsymbol{\beta}$-Benzoxy- $\boldsymbol{N}^{\alpha}$-Nps-MeTyr(MOM)-OMe (erythro) (7b) $\mathrm{Et}_{3} \mathrm{~N}(1.38$ $\mathrm{g}, 12 \mathrm{mmol})$, DMAP $(0.45 \mathrm{~g}, 3.6 \mathrm{mmol})$ and benzoyl chloride $(1.92 \mathrm{~g}$, $14 \mathrm{mmol})$ were added to a solution of $6 \mathbf{b}(3.85 \mathrm{~g}, 9.1 \mathrm{mmol})$ in $\mathrm{CH}_{2} \mathrm{Cl}_{2}$ $(30 \mathrm{ml})$. The mixture was stirred for $16 \mathrm{~h}$ at room temperature, then 3-dimethylaminopropylamine $(3.3 \mathrm{~g}, 32 \mathrm{mmol})$ was added. The mixture was concentrated and the residue was dissolved in EtOAc $(30 \mathrm{ml})$. This solution was washed with dilute $\mathrm{HCl}, \mathrm{NaHCO}_{3}$ and $\mathrm{H}_{2} \mathrm{O}$, then evaporated, and the residue was purified by silica gel column chromatography $(150 \mathrm{~g}, n$-hexane-EtOAc $(5: 2))$ to give $7 \mathbf{b}(4.49 \mathrm{~g}, 93.6 \%) . R f$ 0.23 (EtOAc- $n$-hexane $(1: 2)$ ). IR (film) $\mathrm{cm}^{-1}: 2950,1740,1515$. FAB-MS $m / z: 527(\mathrm{M}+\mathrm{H})^{+}$. HR-FAB-MS $m / z$ : Calcd for $\mathrm{C}_{26} \mathrm{H}_{27} \mathrm{~N}_{2} \mathrm{O}_{8} \mathrm{~S}$ $(\mathrm{M}+\mathrm{H})^{+}:$527.1488. Found: 527.1512 .

B-Benzoxy-MeTyr(MOM)-OMe (threo) (8a) Thiophenol $(4.8 \mathrm{ml}$ $46.7 \mathrm{mmol})$ and TFA $(2.5 \mathrm{ml}, 32.5 \mathrm{mmol})$ were added to a solution of $7 \mathrm{a}$ $(4.94 \mathrm{~g}, 9.4 \mathrm{mmol})$ in $\mathrm{CH}_{2} \mathrm{Cl}_{2}(50 \mathrm{ml})$ at $0^{\circ} \mathrm{C}$. The mixture was stirred for $30 \mathrm{~min}$, then $\mathrm{NaHCO}_{3}$ was added. The organic layer was washed with $\mathrm{NaHCO}_{3}$ and brine, and evaporated. The residue was purified on a silica gel column $\left(100 \mathrm{~g}, 5 \% \mathrm{MeOH} / \mathrm{CHCl}_{3}\right)$ to give $8 \mathrm{a}(3.22 \mathrm{~g}$, 91.9\%). Rf 0.31 (EtOAc-n-hexane (l:1)). IR (film) $\mathrm{cm}^{-1}: 2950,1730$ 1510. ${ }^{1} \mathrm{H}-\mathrm{NMR}\left(\mathrm{CD}_{3} \mathrm{OD}\right) \delta: 2.35(3 \mathrm{H}, \mathrm{br} \mathrm{s}), 3.42(3 \mathrm{H}, \mathrm{s}), 3.60(3 \mathrm{H}, \mathrm{s})$, $3.75(1 \mathrm{H}, \mathrm{d}, J=5 \mathrm{~Hz}), 5.15(2 \mathrm{H}, \mathrm{s}), 6.16(1 \mathrm{H}, \mathrm{d}, J=5 \mathrm{~Hz}), 7.02,7.37$ (each $2 \mathrm{H}, \mathrm{d}, J=9 \mathrm{~Hz}), 7.49(2 \mathrm{H}, \mathrm{m}), 7.62(1 \mathrm{H}, \mathrm{m}), 8.08(2 \mathrm{H}, \mathrm{dd}, J=8.5$, $1 \mathrm{~Hz})$. FAB-MS $m / z: 374(\mathrm{M}+\mathrm{H})^{+}$. HR-FAB-MS $m / z$ : Calcd for $\mathrm{C}_{20} \mathrm{H}_{24} \mathrm{NO}_{6}(\mathrm{M}+\mathrm{H})^{+}:$374.1603. Found: 374.1615.

B-Benzoxy-MeTyr(MOM)-OMe (erythro) (8b) Thiophenol $(7 \mathrm{ml}$, $68 \mathrm{mmol})$ and TFA $(3 \mathrm{ml})$ were added to a solution of $7 \mathrm{~b}(4.48 \mathrm{~g}, 8.5 \mathrm{mmol})$ in $\mathrm{CH}_{2} \mathrm{Cl}_{2}(50 \mathrm{ml})$ at $0{ }^{\circ} \mathrm{C}$. The mixture was stirred for $30 \mathrm{~min}$, then $\mathrm{NaHCO}_{3}$ was added. The organic layer was washed with $\mathrm{NaHCO}_{3}$ and brine, and evaporated. The residue was purified on a silica gel column $\left(100 \mathrm{~g}, 5 \% \mathrm{MeOH} / \mathrm{CHCl}_{3}\right)$ to give $\mathbf{8 b}(2.29 \mathrm{~g}, 72.1 \%)$. Rf 0.25 (EtOAc- $n$-hexane $(1: 1))$. IR (film) $\mathrm{cm}^{-1}: 2950,1730,1515 .{ }^{1} \mathrm{H}-\mathrm{NMR}$ $\left(\mathrm{CD}_{3} \mathrm{OD}\right) \delta: 2.35(3 \mathrm{H}, \mathrm{s}), 3.42(3 \mathrm{H}, \mathrm{s}), 3.68(3 \mathrm{H}, \mathrm{s}), 3.70(1 \mathrm{H}, \mathrm{d}, J=7 \mathrm{~Hz})$, $5.17(2 \mathrm{H}, \mathrm{s}), 6.10(1 \mathrm{H}, \mathrm{d}, J=7 \mathrm{~Hz}), 7.04,7.37($ each $2 \mathrm{H}, \mathrm{d}, J=9 \mathrm{~Hz})$, $7.50(2 \mathrm{H}, \mathrm{m}), 7.63(1 \mathrm{H}, \mathrm{m}), 8.05(2 \mathrm{H}, \mathrm{dd}, J=8.5,1 \mathrm{~Hz})$. FAB-MS $m / z$ : $374(\mathrm{M}+\mathrm{H})^{+}$. HR-FAB-MS $m / z$ : Calcd for $\mathrm{C}_{20} \mathrm{H}_{24} \mathrm{NO}_{6}(\mathrm{M}+\mathrm{H})^{+}$: 374.1603. Found: 374.1619 .

Cbz-Thr- $\boldsymbol{\beta}$-benzoxy-MeTyr(MOM)-OMe (threo) (9a) $\operatorname{EEDQ}(2.9 \mathrm{~g}$ $11.7 \mathrm{mmol})$ was added to a solution of $\mathrm{Cbz}-\mathrm{Thr}-\mathrm{OH}(3.7 \mathrm{~g}, 14.6 \mathrm{mmol})$ and $8 \mathrm{a}(3.11 \mathrm{~g}, 8.3 \mathrm{mmol})$ in $\mathrm{CH}_{2} \mathrm{Cl}_{2}(50 \mathrm{ml})$ and the mixture was stirred for $20 \mathrm{~h}$ at room temperature, then evaporated. The residue was dissolved in EtOAc $(50 \mathrm{ml})$. This solution was washed with dilute $\mathrm{HCl}, \mathrm{NaHCO}_{3}$ and $\mathrm{H}_{2} \mathrm{O}$, and evaporated. The residue was purified on a silica gel column (100 g, $n$-hexane-EtOAc $(1: 1))$ to give $9 \mathbf{a}(2.04 \mathrm{~g}, 40.2 \%)$. Rf $0.36(3 \%$ $\mathrm{MeOH} / \mathrm{CHCl}_{3}$ ). IR (film) $\mathrm{cm}^{-1}$ : 3400, 2950, 1740 (shoulder), 1720 . ${ }^{1} \mathrm{H}-\mathrm{NMR}\left(\mathrm{CDCl}_{3}\right)$ (three conformers $(4: 2: 1)$ existed in the solvent) major conformer $\delta: 0.97(3 \mathrm{H}, \mathrm{d}, J=6 \mathrm{~Hz}), 3.28(3 \mathrm{H}, \mathrm{s}), 3.44(3 \mathrm{H}, \mathrm{s})$, $3.50(1 \mathrm{H}, \mathrm{m}), 3.63(3 \mathrm{H}, \mathrm{s}), 4.50(1 \mathrm{H}, \mathrm{d}, J=10 \mathrm{~Hz}), 5.08(2 \mathrm{H}, \mathrm{s}), 5.13$ $(2 \mathrm{H}, \mathrm{s}), 5.61(1 \mathrm{H}, \mathrm{d}, J=10 \mathrm{~Hz}), 5.91(1 \mathrm{H}, \mathrm{d}, J=7.5 \mathrm{~Hz}), 6.68(1 \mathrm{H}, \mathrm{d}$, $J=7.5 \mathrm{~Hz}), 7.02(2 \mathrm{H}, \mathrm{d}, J=8 \mathrm{~Hz}), 7.25-7.65(10 \mathrm{H}, \mathrm{m}), 8.01(2 \mathrm{H}, \mathrm{m})$. FAB-MS $m / z: 609(\mathrm{M}+\mathrm{H})^{+}$. HR-FAB-MS $m / z$ : Calcd for $\mathrm{C}_{32} \mathrm{H}_{37} \mathrm{~N}_{2} \mathrm{O}_{10}$ $(\mathrm{M}+\mathrm{H})^{+}:$609.2448. Found: 609.2481.

Cbz-Thr- $\beta$-benzoxy-MeTyr(MOM)-OMe (erythro) (9b) A solution of Cbz-Thr-OH $(0.95 \mathrm{~g}, 3.75 \mathrm{mmol})$ and $8 \mathrm{~b}(1.40 \mathrm{~g}, 3.75 \mathrm{mmol})$ in $\mathrm{CH}_{2} \mathrm{Cl}_{2}$ $(20 \mathrm{ml})$ was treated with EEDQ $(0.93 \mathrm{~g}, 3.75 \mathrm{mmol})$. The mixture was stirred for $14 \mathrm{~h}$ at room temperature, then evaporated. The residue was dissolved in EtOAc $(30 \mathrm{ml})$. This solution was washed with dilute $\mathrm{HCl}$ $\mathrm{NaHCO}_{3}$ and $\mathrm{H}_{2} \mathrm{O}$, then evaporated. The residue was purified on a silica gel column $(50 \mathrm{~g}, n$-hexane-EtOAc $(1: 1))$ to give $9 \mathrm{~b}(1.12 \mathrm{~g}, 49.1 \%) . R f$ $0.23\left(3 \% \mathrm{MeOH} / \mathrm{CHCl}_{3}\right)$. IR (film) $\mathrm{cm}^{-1}: 2950,1740,1730$ (shoulder). ${ }^{1} \mathrm{H}-\mathrm{NMR}\left(\mathrm{CDCl}_{3}\right)$ (two conformers $(1: 1)$ existed in the solvent) $\delta: 0.97$ $(3 \mathrm{H}, \mathrm{d}, J=6 \mathrm{~Hz}), 1.04(3 \mathrm{H}, \mathrm{d}, J=6 \mathrm{~Hz}), 2.93(3 \mathrm{H}, \mathrm{s}), 2.99(3 \mathrm{H}, \mathrm{s}), 3.36$ $(1 \mathrm{H}, \mathrm{m}), 3.40(3 \mathrm{H}, \mathrm{s}), 3.43(3 \mathrm{H}, \mathrm{s}), 3.73(6 \mathrm{H}, \mathrm{s}), 4.02(1 \mathrm{H}, \mathrm{m}), 4.33(2 \mathrm{H}$, $\mathrm{m}), 4.0-5.2(8 \mathrm{H}, \mathrm{m}), 5.60(4 \mathrm{H}, \mathrm{m}), 6.46(2 \mathrm{H}, \mathrm{m}), 7.0(4 \mathrm{H}, \mathrm{m}), 7.25-7.65$ $(20 \mathrm{H}, \mathrm{m}), 8.02(4 \mathrm{H}, \mathrm{m})$. FAB-MS $m / z: 609(\mathrm{M}+\mathrm{H})^{+}$. HR-FAB-MS $m / z$ : Calcd for $\mathrm{C}_{32} \mathrm{H}_{37} \mathrm{~N}_{2} \mathrm{O}_{10}(\mathrm{M}+\mathrm{H})^{+}:$609.2448. Found: 609.2479 .

Cbz-Thr-(Z)AMeTyr(MOM)-OMe (10) DBU $(0.30 \mathrm{~g}, 2.0 \mathrm{mmol})$ was added to a solution of $9 \mathrm{a}(1.20 \mathrm{~g}, 2.0 \mathrm{mmol})$ in toluene $(20 \mathrm{ml})$. The mixture was stirred for $0.5 \mathrm{~h}$ at room temperature, then $7 \% \mathrm{HCl}(10 \mathrm{ml})$ was added. The organic layer was washed with $\mathrm{H}_{2} \mathrm{O}$ and $\mathrm{NaHCO}_{3}$, dried $\left(\mathrm{MgSO}_{4}\right)$, and evaporated to give $10(0.95 \mathrm{~g}, 99 \%)$ as a colorless oil. Rf $0.25\left(3 \% \mathrm{MeOH} / \mathrm{CHCl}_{3}\right) .[\alpha]_{\mathrm{D}}^{23}-7.7^{\circ}(c=0.64, \mathrm{MeOH})$. IR (film) $\mathrm{cm}^{-1}: 3400,2950,1720 .{ }^{1} \mathrm{H}-\mathrm{NMR}\left(\mathrm{CDCl}_{3}\right)$ (three conformers $(4: 3: 1)$ existed in the solvent) major conformer $\delta: 0.90(3 \mathrm{H}, \mathrm{d}, J=7 \mathrm{~Hz}), 3.15$ $(3 \mathrm{H}, \mathrm{s}), 3.48(3 \mathrm{H}, \mathrm{s}), 3.70(3 \mathrm{H}, \mathrm{s}), 3.68(1 \mathrm{H}, \mathrm{m}), 4.23(1 \mathrm{H}, \mathrm{dd}, J=1$, $10 \mathrm{~Hz}), 5.08(2 \mathrm{H}, \mathrm{m}), 5.22(2 \mathrm{H}, \mathrm{m}), 5.53(1 \mathrm{H}, \mathrm{d}, J=10 \mathrm{~Hz}), 6.98-7.50$ $(9 \mathrm{H}, \mathrm{m}), 7.69(1 \mathrm{H}, \mathrm{s})$. FAB-MS $m / z: 487(\mathrm{M}+\mathrm{H})^{+}$. HR-FAB-MS $m / z$ : Calcd for $\mathrm{C}_{25} \mathrm{H}_{31} \mathrm{~N}_{2} \mathrm{O}_{8}(\mathrm{M}+\mathrm{H})^{+}:$487.2080. Found: 487.2094. The same compound 10 was obtained in a similar manner from $9 \mathrm{~b}$ (reaction time $2.5 \mathrm{~h})$.

Cbz-Thr(TBDMS)-(Z)AMeTyr(MOM)-OMe (11) tert-Butyldimethylsilyl chloride $(0.75 \mathrm{~g}, 5.0 \mathrm{mmol})$ and imidazole $(0.34 \mathrm{~g}, 5.0 \mathrm{mmol})$ were added to a solution of $10(1.0 \mathrm{~g}, 2.0 \mathrm{mmol})$ in DMF $(10 \mathrm{ml})$. The mixture was stirred for $16 \mathrm{~h}$ at room temperature, then EtOAc $(30 \mathrm{ml})$ and ice $(50 \mathrm{~g})$ were added. The organic layer was washed with dilute $\mathrm{HCl}$, $\mathrm{NaHCO}_{3}$ and $\mathrm{H}_{2} \mathrm{O}$, and evaporated. The residue was purified on a silica gel column $\left(30 \mathrm{~g}, \mathrm{CHCl}_{3}\right)$ to give $11(1.21 \mathrm{~g}, 98 \%$ ). Rf 0.27 (AcOEt$n$-hexane $(1: 2)) .[\alpha]_{\mathrm{D}}^{23}-55.9^{\circ}(c=0.56, \mathrm{MeOH})$. IR (film) $\mathrm{cm}^{-1}: 2950$, 1720. ${ }^{1} \mathrm{H}-\mathrm{NMR}\left(\mathrm{CDCl}_{3}\right)$ (two conformer $(1: 1)$ existed in the solvent) $\delta:-0.07(3 \mathrm{H}, \mathrm{s}),-0.04(3 \mathrm{H}, \mathrm{s}), 0.03(3 \mathrm{H}, \mathrm{s}), 0.05(3 \mathrm{H}, \mathrm{s}), 0.85(18 \mathrm{H}$, s), $0.91(3 \mathrm{H}, \mathrm{d}, J=6 \mathrm{~Hz}), 1.10(3 \mathrm{H}, \mathrm{d}, J=6 \mathrm{~Hz}), 3.12(3 \mathrm{H}, \mathrm{s}), 3.14(3 \mathrm{H}$, s), $3.44(3 \mathrm{H}, \mathrm{s}), 3.50(3 \mathrm{H}, \mathrm{s}), 3.72(3 \mathrm{H}, \mathrm{s}), 3.87(\mathrm{lH}, \mathrm{m}), 3.91(3 \mathrm{H}, \mathrm{s})$, $4.04(1 \mathrm{H}, \mathrm{m}), 4.20(1 \mathrm{H}, \mathrm{dd}, J=4,9 \mathrm{~Hz}), 4.31(1 \mathrm{H}, \mathrm{dd}, J=4,9 \mathrm{~Hz}), 4.65$ $(1 \mathrm{H}, \mathrm{d}, J=12 \mathrm{~Hz}), 4.80(1 \mathrm{H}, \mathrm{d}, J=12 \mathrm{~Hz}), 5.10(2 \mathrm{H}, \mathrm{m}), 5.12(2 \mathrm{H}, \mathrm{s})$, $5.18(1 \mathrm{H}, \mathrm{d}, J=9 \mathrm{~Hz}), 5.24(2 \mathrm{H}, \mathrm{s}), 5.44(1 \mathrm{H}, \mathrm{d}, J=9 \mathrm{~Hz}), 7.03(2 \mathrm{H}, \mathrm{d}$, $J=8 \mathrm{~Hz}), 7.10(2 \mathrm{H}, \mathrm{d}, J=8 \mathrm{~Hz}), 7.18-7.44(10 \mathrm{H}, \mathrm{m}), 7.44(2 \mathrm{H}, \mathrm{d}$, $J=8 \mathrm{~Hz}), 7.55(2 \mathrm{H}, \mathrm{d}, J=8 \mathrm{~Hz}), 7.68(1 \mathrm{H}, \mathrm{s}), 7.72(1 \mathrm{H}, \mathrm{s})$. FAB-MS $m / z$ : $601(\mathrm{M}+\mathrm{H})^{+}$. HR-FAB-MS $m / z$ : Calcd for $\mathrm{C}_{31} \mathrm{H}_{45} \mathrm{~N}_{2} \mathrm{O}_{8} \mathrm{Si}(\mathrm{M}+\mathrm{H})^{+}$: 601.2945. Found: 601.2959

Cbz-Thr(TBDMS)-(Z)AMeTyr(MOM)-OH (12) A solution of 11 $(0.95 \mathrm{~g}, 1.6 \mathrm{mmol})$ in $\mathrm{MeOH}$ was treated with $1 \mathrm{~N} \mathrm{NaOH}(4.8 \mathrm{ml})$, and the mixture was stirred for $2 \mathrm{~d}$ at $30^{\circ} \mathrm{C}$ then evaporated. The residue was dissolved in EtOAc $(20 \mathrm{ml})$. This solution was washed with dilute $\mathrm{HCl}$ and $\mathrm{H}_{2} \mathrm{O}$, and evaporated to gave $\mathbf{1 2}$ as a colorless gum $(0.81 \mathrm{~g}$, $87.3 \%)$. Rf $0.34\left(10 \% \mathrm{MeOH} / \mathrm{CHCl}_{3}\right) .[\alpha]_{\mathrm{D}}^{23}-82.9^{\circ}(c=1.06, \mathrm{MeOH})$. IR (film) $\mathrm{cm}^{-1}: 3300,2950,1720,1700$ (shoulder). ${ }^{1} \mathrm{H}-\mathrm{NMR}\left(\mathrm{CDCl}_{3}\right)$ (two conformers $(1: 1)$ existed in the solvent) $\delta:-0.05(3 \mathrm{H}, \mathrm{s}),-0.03$ $(3 \mathrm{H}, \mathrm{s}), 0.03(3 \mathrm{H}, \mathrm{s}), 0.05(3 \mathrm{H}, \mathrm{s}), 0.85(18 \mathrm{H}, \mathrm{s}), 0.93(3 \mathrm{H}, \mathrm{d}, J=6 \mathrm{~Hz})$, $1.12(3 \mathrm{H}, \mathrm{d}, J=6 \mathrm{~Hz}), 3.14(3 \mathrm{H}, \mathrm{s}), 3.16(3 \mathrm{H}, \mathrm{s}), 3.43(3 \mathrm{H}, \mathrm{s}), 3.50(3 \mathrm{H}$, s), $3.90(1 \mathrm{H}, \mathrm{m}), 4.08(1 \mathrm{H}, \mathrm{m}), 4.28(1 \mathrm{H}, \mathrm{dd}, J=4,9 \mathrm{~Hz}), 4.37(1 \mathrm{H}, \mathrm{dd}$, $J=5,9 \mathrm{~Hz}), 4.60(1 \mathrm{H}, \mathrm{d}, J=12 \mathrm{~Hz}), 4.80(1 \mathrm{H}, \mathrm{d}, J=12 \mathrm{~Hz}), 5.07(2 \mathrm{H}$, $\mathrm{m}), 5.13(2 \mathrm{H}, \mathrm{s}), 5.21(1 \mathrm{H}, \mathrm{d}, J=9 \mathrm{~Hz}), 5.25(2 \mathrm{H}, \mathrm{s}), 5.60(1 \mathrm{H}, \mathrm{d}, J=9 \mathrm{~Hz})$, $7.05(2 \mathrm{H}, \mathrm{d}, J=8 \mathrm{~Hz}), 7.12(2 \mathrm{H}, \mathrm{d}, J=8 \mathrm{~Hz}), 7.18-7.43(10 \mathrm{H}, \mathrm{m}), 7.46$ $(2 \mathrm{H}, \mathrm{d}, J=8 \mathrm{~Hz}), 7.58(2 \mathrm{H}, \mathrm{d}, J=8 \mathrm{~Hz}), 7.75(1 \mathrm{H}, \mathrm{s}), 7.83(1 \mathrm{H}, \mathrm{s})$. FAB-MS $m / z: 587(\mathrm{M}+\mathrm{H})^{+}$. HR-FAB-MS $m / z$ : Calcd for $\mathrm{C}_{30} \mathrm{H}_{43} \mathrm{~N}_{2} \mathrm{O}_{8}$ $\mathrm{Si}(\mathrm{M}+\mathrm{H})^{+}:$587.2788. Found: 587.2813.

Cbz-Thr(TBDMS)-(Z)AMeTyr(MOM)-Leu-D-Phe-OTce (13) $\mathrm{Et}_{3} \mathrm{~N}(1.25 \mathrm{~g}, 12.3 \mathrm{mmol})$ and $\operatorname{EEDQ}(3.04 \mathrm{~g}, 12.3 \mathrm{mmol})$ were added to a mixture of $12(1.60 \mathrm{~g}, 2.73 \mathrm{mmol})$ and $22(5.50 \mathrm{~g}, 12.3 \mathrm{mmol})$ in $\mathrm{CH}_{2} \mathrm{Cl}_{2}$ $(50 \mathrm{ml})$ and the mixture was stirred for $15 \mathrm{~h}$ at room temperature. A white solid was filtered off, then $22(2.23 \mathrm{~g}, 5 \mathrm{mmol}), \mathrm{Et}_{3} \mathrm{~N}(0.50 \mathrm{~g}, 5 \mathrm{mmol})$ and EEDQ (1.24 g, $5 \mathrm{mmol}$ ) were added to the filtrate. The mixture was stirred for $18 \mathrm{~h}$ and evaporated. The residue was dissolved in EtOAc $(50 \mathrm{ml})$ and this solution was washed with dilute $\mathrm{HCl}, \mathrm{NaHCO}_{3}$ and $\mathrm{H}_{2} \mathrm{O}$, and evaporated. The residue was purified on a silica gel column $(100 \mathrm{~g}, n$-hexane-EtOAc $(2: 1))$ to give $13(0.87 \mathrm{~g}, 32.6 \%)$, Rf 0.30 (EtOAc- $n$-hexane $(2: 3)) .[\alpha]_{\mathrm{D}}^{23}-31.5^{\circ}(c=1.07, \mathrm{MeOH})$. IR (film) $\mathrm{cm}^{-1}: 2950,1760,1740$ (shoulder), 1720, 1660. UV $\lambda_{\max }(\mathrm{MeOH}) \mathrm{nm}$ (e): $305(18500) .{ }^{1} \mathrm{H}-\mathrm{NMR}\left(\mathrm{CDCl}_{3}\right) \delta:-0.22(3 \mathrm{H}, \mathrm{s}),-0.13(3 \mathrm{H}, \mathrm{s})$, $0.70(3 \mathrm{H}, \mathrm{d}, J=6 \mathrm{~Hz}), 0.83(9 \mathrm{H}, \mathrm{s}), 0.92(3 \mathrm{H}, \mathrm{d}, J=6 \mathrm{~Hz}), 0.95(3 \mathrm{H}, \mathrm{d}$, $J=6 \mathrm{~Hz}), 1.60-1.85(3 \mathrm{H}, \mathrm{m}), 3.01(1 \mathrm{H}, \mathrm{dd}, J=7,14 \mathrm{~Hz}), 3.18(3 \mathrm{H}, \mathrm{s})$, $3.22(1 \mathrm{H}, \mathrm{dd}, J=5,14 \mathrm{~Hz}), 3.32(1 \mathrm{H}, \mathrm{q}, J=6 \mathrm{~Hz}), 3.49(3 \mathrm{H}, \mathrm{s}), 3.81(1 \mathrm{H}$, $\mathrm{d}, J=7 \mathrm{~Hz}), 4.45(1 \mathrm{H}, \mathrm{m}), 4.47(1 \mathrm{H}, \mathrm{d}, J=12 \mathrm{~Hz}), 4.64(1 \mathrm{H}, \mathrm{d}, J=12 \mathrm{~Hz})$, $4.92(1 \mathrm{H}, \mathrm{m}), 4.99(1 \mathrm{~Hz}, \mathrm{~d}, J=12 \mathrm{~Hz}), 5.14(1 \mathrm{H}, \mathrm{d}, J=12 \mathrm{~Hz}), 5.21(2 \mathrm{H}$, s), $5.92(1 \mathrm{H}, \mathrm{d}, J=7 \mathrm{~Hz}), 7.10(2 \mathrm{H}, \mathrm{d}, J=8.5 \mathrm{~Hz}), 7.17(2 \mathrm{H}, \mathrm{d}, J=8 \mathrm{~Hz})$, $7.20-7.4(11 \mathrm{H}, \mathrm{m}), 7.66(1 \mathrm{H}, \mathrm{s}), 7.70(1 \mathrm{H}, \mathrm{d}, J=7.5 \mathrm{~Hz})$. FAB-MS $m / z$ : $977(\mathrm{M}+\mathrm{H})^{+}$. HR-FAB-MS $m / z$ : Calcd for $\mathrm{C}_{47} \mathrm{H}_{64} \mathrm{Cl}_{3} \mathrm{~N}_{4} \mathrm{O}_{10} \mathrm{Si}$ $(\mathrm{M}+\mathrm{H})^{+}:$977.3457. Found: 977.3463. Amino acid ratios in an acid hydrolysate: Thr 0.80, Leu 1.00, Phe 1.07, $\mathrm{MeNH}_{2} 1.12$.

Cbz-Thr(TBDMS)-(E)AMeTyr(MOM)-Leu-D-Phe-OTce (14) A solution of $13(0.85 \mathrm{~g}, 0.87 \mathrm{mmol})$ in toluene $(100 \mathrm{ml})$ and acetone $(10 \mathrm{ml})$ 
was irradiated with a UV lamp $(100 \mathrm{~W})$ for $1.5 \mathrm{~h}$ at $0^{\circ} \mathrm{C}$. The solvent was evaporated, and the residue was purified on a silica gel column (50 g, $n$-hexane-EtOAc (2:1)) to give $14(0.18 \mathrm{~g}, 21.2 \%)$ and $13(0.42 \mathrm{~g}$, 49.5\%). 14: $\mathrm{mp} 40-42^{\circ} \mathrm{C} . R f 0.22(n$-hexane-EtOAc $(2: 1))$. $[\alpha]_{\mathrm{D}}^{21}-23.6^{\circ}$ $(c=0.5, \mathrm{MeOH})$. IR $(\mathrm{KBr}) \mathrm{cm}^{-1}: 3300,1740$ (shoulder), 1640. UV $\lambda_{\max }$ $(\mathrm{MeOH}) \mathrm{nm}(\varepsilon): 284(8865) .{ }^{1} \mathrm{H}-\mathrm{NMR}\left(\mathrm{CDCl}_{3}\right)$ (two conformers $(2: 1)$ existed in the solvent) major conformer $\delta: 0.10(3 \mathrm{H}, \mathrm{s}), 0.83(3 \mathrm{H}, \mathrm{d}$, $J=6 \mathrm{~Hz}), 0.86(3 \mathrm{H}, \mathrm{d}, J=6 \mathrm{~Hz}), 0.90(9 \mathrm{H}, \mathrm{s}), 1.13(3 \mathrm{H}, \mathrm{d}, J=6 \mathrm{~Hz})$, $1.40-1.76(3 \mathrm{H}, \mathrm{m}), 3.01(1 \mathrm{H}, \mathrm{dd}, J=9,14 \mathrm{~Hz}), 3.04(3 \mathrm{H}, \mathrm{s}), 3.27(1 \mathrm{H}$, $\mathrm{dd}, J=5,14 \mathrm{~Hz}), 3.46(3 \mathrm{H}, \mathrm{s}), 4.25(1 \mathrm{H}, \mathrm{m}), 4.44(1 \mathrm{H}, \mathrm{m}), 4.47(1 \mathrm{H}, \mathrm{d}$, $J=8 \mathrm{~Hz}), 4.64(1 \mathrm{H}, \mathrm{d}, J=12 \mathrm{~Hz}), 4.84(1 \mathrm{H}, \mathrm{d}, J=12 \mathrm{~Hz}), 4.89(1 \mathrm{H}, \mathrm{m})$, $5.01(1 \mathrm{H}, \mathrm{d}, J=12 \mathrm{~Hz}), 5.14(1 \mathrm{H}, \mathrm{d}, J=12 \mathrm{~Hz}), 5.17(2 \mathrm{H}, \mathrm{s}), 5.83(1 \mathrm{H}$, $\mathrm{d}, J=8 \mathrm{~Hz}), 6.63(1 \mathrm{H}, \mathrm{s}), 6.97(2 \mathrm{H}, \mathrm{d}, J=8.5 \mathrm{~Hz}), 7.00-7.37(11 \mathrm{H}, \mathrm{m}), 7.38$ $(2 \mathrm{H}, \quad \mathrm{d}, \quad J=8.5 \mathrm{~Hz}), 7.83(1 \mathrm{H}, \mathrm{d}, \quad J=7 \mathrm{~Hz}) . \quad$ FAB-MS $m / z: 977$ $(\mathrm{M}+\mathrm{H})^{+}$. HR-FAB-MS $m / z$ : Calcd for $\mathrm{C}_{47} \mathrm{H}_{64} \mathrm{Cl}_{3} \mathrm{~N}_{4} \mathrm{O}_{10} \mathrm{Si}(\mathrm{M}+\mathrm{H})^{+}$: 977.3457. Found: 977.3472. Amino acid ratios in an acid hydrolysate: Thr 0.84, Leu 1.00, Phe 1.01, $\mathrm{MeNH}_{2} 1.16$.

Cbz-Thr-(E)AMeTyr(MOM)-Leu-D-Phe-OTce (15) Compound 14 $(0.17 \mathrm{~g}, 0.17 \mathrm{mmol})$ was dissolved in $67 \% \mathrm{AcOH}(10 \mathrm{ml})$, and the solution was stirred for $28 \mathrm{~h}$ at $25^{\circ} \mathrm{C}$, then concentrated. The residue was dissolved in EtOAc ( $20 \mathrm{ml})$. This solution was washed with $\mathrm{NaHCO}_{3}$ and $\mathrm{H}_{2} \mathrm{O}$, and evaporated. The residue was rinsed with $n$-hexane to give $15(0.15 \mathrm{~g}$, $99.9 \%) . \mathrm{mp} 56-59^{\circ} \mathrm{C} . R f 0.18(n$-hexane-EtOAc $(1: 1)) .[\alpha]_{\mathrm{D}}^{20}-44.4^{\circ}$ $(c=0.5, \mathrm{MeOH})$. IR $\left(\mathrm{KBr} \mathrm{cm}^{-1}: 3250,1740\right.$ (shoulder), 1635. ${ }^{1} \mathrm{H}-\mathrm{NMR}$ $\left(\mathrm{CDCl}_{3}\right) \delta: 0.84(3 \mathrm{H}, \mathrm{d}, J=6 \mathrm{~Hz}), 0.85(3 \mathrm{H}, \mathrm{d}, J=6 \mathrm{~Hz}), 1.15(3 \mathrm{H}, \mathrm{d}$, $J=6 \mathrm{~Hz}), 1.35-1.70(3 \mathrm{H}, \mathrm{m}), 3.04(1 \mathrm{H}, \mathrm{dd}, J=8,14 \mathrm{~Hz}), 3.08(3 \mathrm{H}, \mathrm{s})$, $3.27(1 \mathrm{H}, \mathrm{dd}, J=5,14 \mathrm{~Hz}), 3.46(3 \mathrm{H}, \mathrm{s}), 4.21(1 \mathrm{H}, \mathrm{q}, J=6 \mathrm{~Hz}), 4.44(1 \mathrm{H}$, $\mathrm{m}), 4.61(1 \mathrm{H}, \mathrm{d}, J=8 \mathrm{~Hz}), 4.65(1 \mathrm{H}, \mathrm{d}, J=12 \mathrm{~Hz}), 4.84(1 \mathrm{H}, \mathrm{d}, J=12 \mathrm{~Hz})$, $4.92(1 \mathrm{H}, \mathrm{m}), 5.02(1 \mathrm{H}, \mathrm{d}, J=13 \mathrm{~Hz}), 5.10(1 \mathrm{H}, \mathrm{d}, J=13 \mathrm{~Hz}), 5.18(2 \mathrm{H}$, s), $5.98(1 \mathrm{H}, \mathrm{d}, J=8 \mathrm{~Hz}), 6.56(1 \mathrm{H}, \mathrm{s}), 6.98(2 \mathrm{H}, \mathrm{d}, J=8.5 \mathrm{~Hz}), 7.00(1 \mathrm{H}$, m), 7.13-7.40 $(12 \mathrm{H}, \mathrm{m}), 8.16\left(1 \mathrm{H}\right.$, br s). FAB-MS $m / z: 863(\mathrm{M}+\mathrm{H})^{+}$. HR-FAB-MS $m / z$ : Calcd for $\mathrm{C}_{41} \mathrm{H}_{50} \mathrm{Cl}_{3} \mathrm{~N}_{4} \mathrm{O}_{10}(\mathrm{M}+\mathrm{H})^{+}: 863.2592$. Found: 863.2622. Amino acid ratios in an acid hydrolysate: Thr 0.83 , Leu 1.00, Phe 1.02, $\mathrm{MeNH}_{2} 1.13$.

Cbz-Thr(Boc-Ser(Bzl))-(E) $\Delta$ MeTyr(MOM)-Leu-D-Phe-OTce (16) Boc-Ser(Bzl)-OH $(0.10 \mathrm{~g}, 0.34 \mathrm{mmol}), \mathrm{EDC} \cdot \mathrm{HCl}(65 \mathrm{mg}, 0.34 \mathrm{mmol})$ and DMAP ( $4 \mathrm{mg}, 0.03 \mathrm{mmol})$ were added to a solution of $15(0.14 \mathrm{~g}$, $0.16 \mathrm{mmol}$ ) in $\mathrm{CH}_{2} \mathrm{Cl}_{2}(5 \mathrm{ml})$ and the mixture was stirred for $12 \mathrm{~h}$ at room temperature. 3-Dimethylaminopropylamine $(50 \mathrm{mg}, 0.5 \mathrm{mmol})$ was added, and the whole was evaporated. The residue was dissolved in EtOAc $(20 \mathrm{ml})$ and this solution was washed with diluted $\mathrm{HCl}$ and $\mathrm{H}_{2} \mathrm{O}$, then evaporated. The residue was purified by silica gel column chromatography $(10 \mathrm{~g}, n$-hexane-EtOAc $(1: 1))$ to give $\mathbf{1 6}(0.16 \mathrm{~g}, 86.5 \%)$. $\mathrm{mp} 51-56^{\circ} \mathrm{C}$. $R f 0.38(n$-hexane-EtOAc $(1: 1))$. $[\alpha]_{\mathrm{D}}^{23}-61.7^{\circ}(c=0.5$, $\mathrm{MeOH})$. IR (KBr) cm ${ }^{-1}$ : 3300, 1730 (shoulder), 1700, 1640, 1495. FAB-MS $m / z: 1140(\mathrm{M}+\mathrm{H})^{+}$. HR-FAB-MS $m / z$ : Calcd for $\mathrm{C}_{56} \mathrm{H}_{69^{-}}$ $\mathrm{Cl}_{3} \mathrm{~N}_{5} \mathrm{O}_{14}(\mathrm{M}+\mathrm{H})^{+}:$1140.3906. Found: 1140.3916. Amino acid ratios in an acid hydrolysate: Thr 0.86, Ser 0.92, Leu 1.00, Phe 1.09, $\mathrm{MeNH}_{2}$ 1.25 .

Cbz-Thr(Boc-Asn-Ser(Bzl))-(E)4MeTyr-Leu-D-Phe-OTce (17) Compound $16(145 \mathrm{mg}, 0.13 \mathrm{mmol})$ was dissolved in $4 \mathrm{~N} \mathrm{HCl}$ in dioxane $(3 \mathrm{ml})$ and anisole $(0.1 \mathrm{ml})$. The mixture was stirred for $30 \mathrm{~min}$ at room temperature, then evaporated. The residue was dissolved in $\mathrm{CH}_{2} \mathrm{Cl}_{2}$ $(3 \mathrm{ml})$. To this solution were added Boc-Asn-OH $(35 \mathrm{mg}, 0.15 \mathrm{mmol})$, $\mathrm{Et}_{3} \mathrm{~N}(13 \mathrm{mg}, 0.13 \mathrm{mmol})$, HOBT $(18 \mathrm{mg}, 0.13 \mathrm{mmol})$ and $\mathrm{EDC} \cdot \mathrm{HCl}$ $(29 \mathrm{mg}, 0.15 \mathrm{mmol})$. The mixture was stirred for $1 \mathrm{~h}$ at room temperature, then $7 \% \mathrm{HCl}(5 \mathrm{ml})$ was added. The organic layer was washed with $\mathrm{H}_{2} \mathrm{O}$, then evaporated, and the residue was purified by preparative TLC $(6 \%$ $\left.\mathrm{MeOH} / \mathrm{CHCl}_{3}\right)$ to give $17(110 \mathrm{mg}, 71.5 \%)$. mp $94-97^{\circ} \mathrm{C}$. Rf 0.44 $\left(\mathrm{CHCl}_{3}-\mathrm{MeOH}(10: 1)\right) .[\alpha]_{\mathrm{D}}^{23}-59.3^{\circ}(c=0.5, \mathrm{MeOH}) . \mathrm{IR}(\mathrm{KBr}) \mathrm{cm}^{-1}$ : 3300,1730 (shoulder), 1650, 1505. FAB-MS $m / z: 1210(\mathrm{M}+\mathrm{H})^{+}$. HR-FAB-MS $m / z$ : Calcd for $\mathrm{C}_{58} \mathrm{H}_{71} \mathrm{Cl}_{3} \mathrm{~N}_{7} \mathrm{O}_{15}(\mathrm{M}+\mathrm{H})^{+}: 1210.4073$. Found: 1210.4092. Amino acid ratios in an acid hydrolysate: Asp 1.10, Thr 1.13, Ser 0.88, Leu 1.00, Phe 1.17, $\mathrm{NH}_{3}$ 1.47, $\mathrm{MeNH}_{2}$ 1.30.

Cbz-Thr(Boc-allo-Thr-Asn-Ser(Bzl))-(E) $\Delta$ MeTyr-Leu-D-Phe-OTce (18) Compound $17(105 \mathrm{mg}, 87 \mu \mathrm{mol})$ was dissolved in $4 \mathrm{~N} \mathrm{HCl}$ in dioxane $(3 \mathrm{ml})$ and anisole $(0.1 \mathrm{ml})$. The mixture was stirred for $30 \mathrm{~min}$ at room temperature, then evaporated, and the residue was dissolved in $\mathrm{CH}_{2} \mathrm{Cl}_{2}(3 \mathrm{ml})$. To this solution were added Boc-allo- $\mathrm{Thr}-\mathrm{OH}(22 \mathrm{mg}$, $0.1 \mathrm{mmol}), \mathrm{Et}_{3} \mathrm{~N}(9 \mathrm{mg}, 90 \mu \mathrm{mol}), \mathrm{HOBT}(12 \mathrm{mg}, 88 \mu \mathrm{mol})$ and $\mathrm{EDC} \cdot \mathrm{HCl}$ $(19 \mathrm{mg}, 0.1 \mathrm{mmol})$. The whole was stirred for $8 \mathrm{~h}$ at room temperature, then $7 \% \mathrm{HCl}(5 \mathrm{ml})$ was added. The organic layer was washed with $\mathrm{H}_{2} \mathrm{O}$, then evaporated, and the residue was purified by preparative TLC $(6 \%$ $\left.\mathrm{MeOH} / \mathrm{CHCl}_{3}\right)$ to give $18(62.1 \mathrm{mg}, 54.6 \%)$. Rf $0.73\left(\mathrm{CHCl}_{3}-\mathrm{MeOH}\right.$
(5:1)). IR (KBr) $\mathrm{cm}^{-1}: 3300,1740$ (shoulder), 1650, 1500. FAB-MS $m / z$ : $1311(\mathrm{M}+\mathrm{H})^{+}$. HR-FAB-MS $m / z$ : Calcd for $\mathrm{C}_{62} \mathrm{H}_{78} \mathrm{Cl}_{3} \mathrm{~N}_{8} \mathrm{O}_{17}$ $(\mathrm{M}+\mathrm{H})^{+}:$1311.4550. Found: 1311.4571. Amino acid ratios in an acid hydrolysate: Asp 1.01, Thr 1.81, Ser 0.76, Leu 1.00, Phe 1.07, $\mathrm{NH}_{3} 0.87$, $\mathrm{MeNH}_{2} 1.19$.

Cbz-Thr(Boc-allo-Thr-Asn-Ser(Bzl))-(E)AMeTyr-Leu-D-Phe-OH (19) Zinc powder $(30 \mathrm{mg})$ was added to a solution of $\mathbf{1 8}(58.5 \mathrm{mg}$, $45 \mu \mathrm{mol})$ in $90 \% \mathrm{AcOH}(1 \mathrm{ml})$. The mixture was stirred for $9 \mathrm{~h}$ at room temperature, then further zinc powder $(30 \mathrm{mg})$ was added to the mixture every hour until the starting material disappeared. The mixture was filtered and the filtrate was evaporated. The residue was dissolved in EtOAc $(10 \mathrm{ml})$ and this solution was washed with $\mathrm{H}_{2} \mathrm{O}$, then evaporated. The residue was purified by preparative TLC (EtOAc-acetone-AcOH$\left.\mathrm{H}_{2} \mathrm{O}(6: 3: 1: 1)\right)$ to give $19(43.5 \mathrm{mg}, 82.6 \%)$. Rf $0.16\left(\mathrm{CHCl}_{3}-\mathrm{MeOH}-\right.$ $\mathrm{AcOH}(10: 1: 0.1))$. $[\alpha]_{\mathrm{D}}^{20}-53.3^{\circ}(c=0.82, \mathrm{MeOH})$. IR $(\mathrm{KBr}) \mathrm{cm}^{-1}$ : 3330,1735 (shoulder), 1650, 1505. FAB-MS $m / z: 1181(\mathrm{M}+\mathrm{H})^{+}$. HR-FAB-MS $m / z$ : Calcd for $\mathrm{C}_{60} \mathrm{H}_{76} \mathrm{~N}_{8} \mathrm{O}_{17}(\mathrm{M}+\mathrm{H})^{+}$: 1181.5406 . Found: 1181.5435. Amino acid ratios in an acid hydrolysate: Asp 1.03, Thr 1.84, Ser 0.80, Leu 1.00, Phe 1.12, $\mathrm{NH}_{3}$ 0.95, $\mathrm{MeNH}_{2}$ 1.29.

Cbz-Thr- $(E) \Delta$ MeTyr-Leu-D-Phe-allo-Thr-Asn-Ser(Bzl) v-Lactone (20) HONSu $(20.4 \mathrm{mg}, 0.18 \mathrm{mmol})$ and $\mathrm{EDC} \cdot \mathrm{HCl}(8.2 \mathrm{mg}, 43 \mu \mathrm{mol})$ were added to a solution of $19(42 \mathrm{mg}, 36 \mu \mathrm{mol})$ in $\mathrm{CH}_{2} \mathrm{Cl}_{2}(4 \mathrm{ml})$ and DMF $(0.1 \mathrm{ml})$. The mixture was stirred for $15 \mathrm{~h}$ at room temperature, then $\mathrm{EDC} \cdot \mathrm{HCl}(4 \mathrm{mg}, 20 \mu \mathrm{mol})$ was added every $1.5 \mathrm{~h}$ until the starting material disappeared. The solvent was evaporated and the residue was dissolved in EtOAc $(10 \mathrm{ml})$. This solution was washed with diluted $\mathrm{HCl}$ and water, dried over $\mathrm{MgSO}_{4}$, and evaporated. The residue was dissolved in TFA $(1 \mathrm{ml})$ and anisole $(0.1 \mathrm{ml})$. This mixture was stirred for $30 \mathrm{~min}$ at room temperature, then evaporated. The residue was dissolved in DMF $(2 \mathrm{ml})$ and the solution was added to pyridine $(40 \mathrm{ml})$. The reaction mixture was stirred for $16 \mathrm{~h}$ at room temperature, then evaporated, and the residue was purified by preparative TLC $\left(\mathrm{CHCl}_{3}-\mathrm{MeOH}(10: 1)\right)$ to give $20(15.2 \mathrm{mg}, 40.2 \%)$. Rf $0.77\left(\mathrm{CHCl}_{3}-\mathrm{MeOH}-\mathrm{H}_{2} \mathrm{O}(65: 25: 4)\right)$. $[\alpha]_{\mathrm{D}}^{23}+18.0^{\circ}(c=0.1, \mathrm{MeOH}), \mathrm{IR}(\mathrm{KBr}) \mathrm{cm}^{-1}: 3300,1730$ (shoulder), 1635, 1510. FAB-MS $m / z: 1063(\mathrm{M}+\mathrm{H})^{+}$. HR-FAB-MS $m / z$ : Calcd for $\mathrm{C}_{55} \mathrm{H}_{67} \mathrm{~N}_{8} \mathrm{O}_{14}(\mathrm{M}+\mathrm{H})^{+}$: 1063.4776. Found: 1063.4789. Amino acid ratios in an acid hydrolysate: Asp 1.00, Thr 1.72, Ser 0.79, Leu 1.00, Phe 1.08, $\mathrm{NH}_{3} 1.03, \mathrm{MeNH}_{2} 1.27$.

H-Thr-(E) $\Delta$ MeTyr-Leu-D-Phe-allo-Thr-Asn-Ser $v$-Lactone Acetate (21) Compound $20(22 \mathrm{mg}, 21 \mu \mathrm{mol})$ was dissolved in HF-pyridine $(0.8 \mathrm{ml})$ and anisole $(0.2 \mathrm{ml})$ in an $\mathrm{N}_{2}$ gas-bag. The mixture was stirred for $1 \mathrm{~h}$ at room temperature, then several pieces of ice were added and the $\mathrm{pH}$ was adjusted to 8 with $\mathrm{NaHCO}_{3}$. The mixture was applied to a column of Diaion HP-20 $(10 \mathrm{ml})$, which was washed with $\mathrm{H}_{2} \mathrm{O}$, and eluted with $\mathrm{MeOH}$. The product was purified by preparative TLC $\left(\mathrm{CHCl}_{3}-\mathrm{MeOH}-\mathrm{H}_{2} \mathrm{O}(3: 1: 0.1)\right)$ to give $21(13.0 \mathrm{mg}, 74.9 \%)$. Rf 0.35 $\left(\mathrm{CHCl}_{3}-\mathrm{MeOH}-\mathrm{H}_{2} \mathrm{O}(3: 1: 0.1)\right)$. IR ( $\left.\mathrm{KBr}\right) \mathrm{cm}^{-1}: 3350,1720$ (shoulder), $1635,1510 .[\alpha]_{\mathrm{D}}^{23}-90.6^{\circ}(c=0.1, \mathrm{MeOH})$. FAB-MS $m / z: 839(\mathrm{M}+\mathrm{H})^{+}$. HR-FAB-MS $m / z$ : Calcd for $\mathrm{C}_{40} \mathrm{H}_{55} \mathrm{~N}_{8} \mathrm{O}_{12}(\mathrm{M}+\mathrm{H})^{+}:$: 839.3939. Found: 839.3952. Amino acid ratios in an acid hydrolysate: Asp 1.07, Thr 1.89, Ser 0.84, Leu 1.00, Phe 1.10, $\mathrm{NH}_{3} 0.98, \mathrm{MeNH}_{2} 1.34$.

$N$-2-(1(Z)-Pentenyl)-cinnamoyl-Thr- $(E) \Delta$ MeTyr-Leu-D-Phe-alloThr-Asn-Ser $v$-Lactone (WS9326A, 1) A solution of $21(6.0 \mathrm{mg}$, $6.7 \mu \mathrm{mol})$ in $\mathrm{CH}_{2} \mathrm{Cl}_{2}(1.5 \mathrm{ml})$, BSA $(30 \mathrm{ml}, 127 \mathrm{mmol})$ and DMF $(0.3 \mathrm{ml})$ was treated with $0.02 \mathrm{M} 2-(1$-pentenyl)cinnamoyl chloride $(0.4 \mathrm{ml})$. The mixture was stirred for $1 \mathrm{~h}$ at room temperature, then DMAP $(0.1 \mathrm{mg})$ was added. Further 2-(1-pentenyl)cinnamoyl chloride was added to the mixture every $30 \mathrm{~min}$ until the starting material disappeared. Then dilute $\mathrm{HCl}$ was added, and the organic layer was washed with $\mathrm{H}_{2} \mathrm{O}$, and evaporated. The residue was purified by preparative TLC $\left(\mathrm{CHCl}_{3}-\right.$ $\left.\mathrm{MeOH}-\mathrm{H}_{2} \mathrm{O}(65: 25: 4)\right)$ to give $1(0.2 \mathrm{mg}, 2.7 \%)$. Rf $0.59\left(\mathrm{CHCl}_{3}\right.$ $\left.\mathrm{MeOH}-\mathrm{H}_{2} \mathrm{O}(65: 25: 4)\right)$. IR (KBr) cm ${ }^{-1}: 3300,1730$ (shoulder), 1610, 1510. FAB-MS $m / z: 1037(\mathrm{M}+\mathrm{H})^{+}$.

H-Leu-D-Phe-OTce Hydrochloride (22) $\mathrm{EDC} \cdot \mathrm{HCl}(7.8 \mathrm{~g}, 40 \mathrm{mmol})$ and DMAP $(0.5 \mathrm{~g}, 4 \mathrm{mmol})$ were added to a solution of Boc-D-Phe-OH $(9.85 \mathrm{~g}, 37.1 \mathrm{mmol})$ and trichloroethanol $(5.55 \mathrm{~g}, 37.1 \mathrm{mmol})$ in $\mathrm{CH}_{2} \mathrm{Cl}_{2}$ $(100 \mathrm{ml})$ and the mixture was stirred for $1.5 \mathrm{~h}$ at room temperature, then evaporated. The residue was dissolved in $\mathrm{EtOAc}(100 \mathrm{ml})$ and this solution was washed with dilute $\mathrm{HCl}, \mathrm{NaHCO}_{3}$ and $\mathrm{H}_{2} \mathrm{O}$, dried $\left(\mathrm{MgSO}_{4}\right)$, and evaporated. The residue was dissolved in toluene $(100 \mathrm{ml})$ and $4 \mathrm{~N} \mathrm{HCl}$ in EtOAc $(100 \mathrm{ml})$ and the solution was stirred for $1 \mathrm{~h}$ at room temperature, then evaporated to give D-Phe-OTce hydrochloride $(7.2 \mathrm{~g}$, $58.3 \%)$.

A solution of Boc- $\mathrm{Leu}-\mathrm{OH} \cdot \mathrm{H}_{2} \mathrm{O}(5.35 \mathrm{~g}, 21.5 \mathrm{mmol})$ in $\mathrm{CH}_{2} \mathrm{Cl}_{2}$ 
$(50 \mathrm{ml})$ was dried $\left(\mathrm{MgSO}_{4}\right)$ and filtered. D-Phe-OTce hydrochloride $(7.15 \mathrm{~g}, 21.5 \mathrm{mmol}), \mathrm{Et}_{3} \mathrm{~N}(2.17 \mathrm{~g}, 21.5 \mathrm{mmol})$, HOBT $(2.9 \mathrm{~g})$, and EDC $\cdot \mathrm{HCl}(4.5 \mathrm{~g}, 23.5 \mathrm{mmol})$ were added to the filtrate. The mixture was stirred for $1 \mathrm{~h}$ at room temperature, then evaporated. The residue was dissolved in EtOAc. This solution was washed with dilute $\mathrm{HCl}, \mathrm{NaHCO}_{3}$, and $\mathrm{H}_{2} \mathrm{O}$, dried $\left(\mathrm{MgSO}_{4}\right)$, and evaporated to give Boc-Leu-D-Phe-OTce $(10.96 \mathrm{~g})$.

A solution of Boc-Leu-D-Phe-OTce $(7.2 \mathrm{~g}, 14.1 \mathrm{mmol})$ in toluene $(100 \mathrm{ml})$ and $4 \mathrm{~N} \mathrm{HCl} /$ EtOAc $(100 \mathrm{ml})$ was stirred for $30 \mathrm{~min}$ at room temperature. Evaporation of the solvent gave $22(6.2 \mathrm{~g}, 98.7 \%) . \mathrm{mp}$ $190-193{ }^{\circ} \mathrm{C} . \mathrm{IR}(\mathrm{KBr}) \mathrm{cm}^{-1}: 3300,3030,1780,1700 .{ }^{1} \mathrm{H}-\mathrm{NMR}\left(\mathrm{CDCl}_{3}\right)$ $\delta: 0.73(3 \mathrm{H}, \mathrm{d}, J=6 \mathrm{~Hz}), 0.82(3 \mathrm{H}, \mathrm{d}, J=6 \mathrm{~Hz}), 1.03(1 \mathrm{H}, \mathrm{m}), 1.45-1.80$ $(2 \mathrm{H}, \mathrm{m}), 3.08(1 \mathrm{H}, \mathrm{dd}, J=11,14 \mathrm{~Hz}), 3.36(1 \mathrm{H}, \mathrm{dd}, J=5,14 \mathrm{~Hz}), 4.30$ $(1 \mathrm{H}, \mathrm{m}), 4.63(1 \mathrm{H}, \mathrm{d}, J=12 \mathrm{~Hz}), 4.95(1 \mathrm{H}, \mathrm{m}), 4.98(1 \mathrm{H}, \mathrm{d}, J=12 \mathrm{~Hz})$, $7.20-7.40(5 \mathrm{H}, \mathrm{m}), 8.16(3 \mathrm{H}, \mathrm{br} \mathrm{s}), 8.63(1 \mathrm{H}, \mathrm{d}, J=8 \mathrm{~Hz})$. FAB-MS $m / z$ : $409(\mathrm{M}+\mathrm{H})^{+}$. Anal. Calcd for $\mathrm{C}_{17} \mathrm{H}_{23} \mathrm{Cl}_{3} \mathrm{~N}_{2} \mathrm{O}_{3} \cdot \mathrm{HCl}$ C, 45.76; H, 5.42; $\mathrm{N}, 6.28$. Found: $\mathrm{C}, 45.82 ; \mathrm{H}, 5.37 ; \mathrm{N}, 6.26$.

2-(1(Z)-Pentenyl)cinnamoyl Chloride (23) $\left(\mathrm{COCl}_{2}\right)_{2}(0.5 \mathrm{ml})$ and DMF $(0.05 \mathrm{ml})$ were added to a solution of 2-(1(Z)-pentenyl)cinnamic acid $(1.08 \mathrm{~g})$ in $\mathrm{CH}_{2} \mathrm{Cl}_{2}(10 \mathrm{ml})$. The mixture was stirred for $1 \mathrm{~h}$ at room temperature under an $\mathrm{N}_{2}$ atmosphere, then evaporated. The residue was dissolved in hexane and the solution was filtered. The filtrate was evaporated to give 2-(1(Z)-pentenyl)cinnamoyl chloride as a pale yellow oil $(1.15 \mathrm{~g})$. IR (neat) $\mathrm{cm}^{-1}: 1750,1730,1605,1585 .{ }^{1} \mathrm{H}-\mathrm{NMR}\left(\mathrm{CDCl}_{3}\right)$ $\delta: 0.88(3 \mathrm{H}, \mathrm{t}, J=6.5 \mathrm{~Hz}), 1.45(2 \mathrm{H}, \mathrm{m}), 2.06(2 \mathrm{H}, \mathrm{m}), 5.95(1 \mathrm{H}, \mathrm{dt}, J=7$, $11 \mathrm{~Hz}), 6.58(1 \mathrm{H}, \mathrm{d}, J=11 \mathrm{~Hz}), 6.66(1 \mathrm{H}, \mathrm{d}, J=16 \mathrm{~Hz}), 7.25-7.50(3 \mathrm{H}$, m), $7.69(1 \mathrm{H}, \mathrm{m}), 8.12(1 \mathrm{H}, \mathrm{d}, J=16 \mathrm{~Hz})$.

2-Oxazolidone Derivative of 6 Thiophenol $(0.2 \mathrm{ml})$ and TFA $(0.5 \mathrm{ml})$ were added to a solution of $6 \mathrm{a}(0.35 \mathrm{~g}, 0.83 \mathrm{mmol})$ in $\mathrm{CH}_{2} \mathrm{Cl}_{2}$. The mixture was stirred for $10 \mathrm{~min}$ at room temperature, then aqueous $\mathrm{NaHCO}_{3}$ was added. The organic layer was evaporated to give $\beta$-hydroxyMeTyr(MOM)-OMe (0.22 g).

$\beta$-Hydroxy-MeTyr(MOM)-OMe $(0.13 \mathrm{~g}, 0.48 \mathrm{mmol})$ was dissolved in $\mathrm{CH}_{2} \mathrm{Cl}_{2}(5 \mathrm{ml})$, and $\mathrm{Cbz}-\mathrm{Cl}(0.1 \mathrm{ml}, 0.6 \mathrm{mmol})$ and BSA $(0.2 \mathrm{ml}$, $0.81 \mathrm{mmol}$ ) were added. The mixture was stirred for $15 \mathrm{~min}$ at room temperature, then 3-dimethylaminopropylamine $(0.1 \mathrm{ml})$ was added. The whole was evaporated, the residue was dissolved in EtOAc $(10 \mathrm{ml})$, and the solution was washed with $7 \% \mathrm{HCl}, \mathrm{NaHCO}_{3}$ and water, dried $\left(\mathrm{MgSO}_{4}\right)$, and evaporated to give Cbz- $\beta$-hydroxy-MeTyr(MOM)-OMe $(0.19 \mathrm{~g})$.

A solution of Cbz- $\beta$-hydroxy-MeTyr(MOM)-OMe (50 mg, $0.12 \mathrm{mmol}$ ) in $\mathrm{MeOH}$ was treated with $1 \mathrm{~N} \mathrm{NaOH}(0.5 \mathrm{ml})$. The mixture was stirred for $6 \mathrm{~h}$ at $50^{\circ} \mathrm{C}$, and evaporated. The residue was dissolved in EtOAc, and this solution was washed with $7 \% \mathrm{HCl}$, dried $\left(\mathrm{MgSO}_{4}\right)$ and evaporated. The residue was purified by preparative TLC $\left(\mathrm{CHCl}_{3}-\mathrm{MeOH}-\right.$ $\mathrm{AcOH}(10: 1: 0.1))$ to give 5-(4-methoxymethoxyphenyl)-3-methyl-2oxazolidone-4-carboxylic acid (6'a) (21 mg, 60\%). 6'a: ${ }^{1} \mathrm{H}-\mathrm{NMR}$ $\left(\mathrm{CDCl}_{3}-\mathrm{CD}_{3} \mathrm{OD}\right) \delta: 3.02(3 \mathrm{H}, \mathrm{s}), 3.48(3 \mathrm{H}, \mathrm{s}), 4.16(1 \mathrm{H}, \mathrm{d}, J=5 \mathrm{~Hz})$, $4.72(2 \mathrm{H}, \mathrm{s}), 5.46(1 \mathrm{H}, \mathrm{d}, J=5 \mathrm{~Hz}), 7.07(2 \mathrm{H}, \mathrm{d}, J=8 \mathrm{~Hz}), 7.32(2 \mathrm{H}, \mathrm{d}$, $J=8 \mathrm{~Hz}$ )

The same procedure was applied to $\mathbf{6 b}$ to give $\mathbf{6}^{\prime} \mathbf{b}$.

6'b: ${ }^{1} \mathrm{H}$-NMR ( $\left.\mathrm{CDCl}_{3}-\mathrm{CD}_{3} \mathrm{OD}\right) \delta: 2.83(3 \mathrm{H}, \mathrm{s}), 3.38(3 \mathrm{H}, \mathrm{s}), 4.30$ $(1 \mathrm{H}, \mathrm{d}, J=9 \mathrm{~Hz}), 5.09(2 \mathrm{H}, \mathrm{s}), 5.58(1 \mathrm{H}, \mathrm{d}, J=9 \mathrm{~Hz}), 6.92(2 \mathrm{H}, \mathrm{d}, J=8 \mathrm{~Hz})$, $7.23(2 \mathrm{H}, \mathrm{d}, J=8 \mathrm{~Hz})$.

$N$-Stearoyl-Thr- $(E) \Delta$ MeTyr-Leu-D-Phe-allo-Thr-Asn-Ser v-Lactone (24) A solution of $21(11.0 \mathrm{mg}, 12 \mu \mathrm{mol})$ in pyridine (1 ml) was treated with $0.02 \mathrm{M}$ stearoyl chloride in $\mathrm{CH}_{2} \mathrm{Cl}_{2}(0.6 \mathrm{ml})$. The mixture was stirred for $1 \mathrm{~h}$ at room temperature, then further stearoyl chloride was added to the mixture every $1 \mathrm{~h}$ until the starting material disappeared. $\mathrm{MeOH}$ $(2 \mathrm{ml})$ was added to the mixture and the solvent was evaporated. The residue was dissolved in AcOEt $(10 \mathrm{ml})$ and this solution was washed with dilute $\mathrm{HCl}$ and $\mathrm{H}_{2} \mathrm{O}$, and evaporated. The residue was purified by preparative TLC $\left(\mathrm{CHCl}_{3}-\mathrm{MeOH}-\mathrm{H}_{2} \mathrm{O}(3: 1: 0.1)\right)$ to give $24(2.0 \mathrm{mg}$, $13.8 \%)$. $R f 0.67\left(\mathrm{CHCl}_{3}-\mathrm{MeOH}-\mathrm{H}_{2} \mathrm{O}(3: 1: 0.1)\right)$. IR $(\mathrm{KBr}) \mathrm{cm}^{-1}: 3250$, 1720 (shoulder), 1640, 1510. FAB-MS $m / z: 1105(\mathrm{M}+\mathrm{H})^{+}$.

\section{References and Notes}

1) All amino acids are the $L$ enantiomer unless otherwise noted. Standard abbreviations for amino acids, protecting groups and peptides are used [Eur. J. Biochem., 138, 9-37 (1984)]. Other abbreviations include: $\mathrm{Boc}=$ tert -butyloxycarbonyl, Bzl = benzyl, $\mathrm{DMF}=N, N$-dimethylformamide, $\mathrm{EDC}=1$-(3-dimethylaminopropyl)-3-ethylcarbodiimide, $\mathrm{HOBt}=1$-hydroxybenzotriazole, $\mathrm{HONSu}$ $=N$-hydroxysuccinimide, RP-HPLC $=$ reverse-phase high-performance liquid chromatography, $\mathrm{Tce}=2,2,2$-trichloroethyl, TFA $=$ triffuoroacetic acid, TEA $=$ triethylamine.

2) a) Hayashi K., Hashimoto M., Shigematsu N., Nishikawa M., Ezaki M., Yamashita M., Kiyoto S., Okuhara M., Kohsaka M., Imanaka H., J. Antibiot., 45, 1055-1063 (1992); b) Hashimoto M., Hayashi K., Murai M., Fujii T., Nishikawa M., Kiyoto S., Okuhara M., Kohsaka M., Imanaka H., ibid., 45, 1064-1070 (1992).

3) Shigematsu N., Hayashi K., Kayakiri N., Takase S., Hashimoto M., Tanaka H., J. Org. Chem., 58, 170-175 (1993).

4) a) Schmidt U., Lieberknecht A., Wild J., Synthesis, 1988, 159-172; b) Gross E., Meienhofer J. (ed.), "The Peptides," Vol. 5, Academic Press, New York, 1983, pp. 285-339.

5) van Heerden F. R., van Zyl J. J., Rall G. J. H., Brandt E. V., Roux D. G., Tetrahedron Lett., 1978, 661-662.

6) Zervas L., Borovas D., Gazis E., J. Am. Chem. Soc., 85, 3660-3666 (1963).

7) Futagawa S., Inui T., Shiba T., Bull. Chem. Soc. Jpn., 46, 3308-3310 (1973).

8) Belleau D., Malek G., J. Am. Chem. Soc., 90, 1651-1652 (1968).

9) Shimohigashi Y., Stammer C. H., Int. J. Pept. Protein Res., 20, 199-206 (1982).

10) Bregman J., Osaki K., Schmidt G. M. J., Sonntag F. I., J. Chem. Soc., 1964, 2021.

11) Corey E. J., Venkateswarlu A., J. Am. Chem. Soc., 94, 6190-6191 (1972).

12) H-Leu-D-Phe-OTce hydrochloride was prepared from Boc-Leu$\mathrm{OH}$ and $\mathrm{H}-\mathrm{D}-\mathrm{Ph}$-OTce using EDC, followed by deprotection of the Boc group with $\mathrm{HCl} /$ EtOAc (see Experimental section).

13) Nitz T. J., Holt E. M., Stammer C. H., J. Org. Chem., 46, 2667-2671 (1981).

14) The $\triangle \mathrm{MeTyr}$ unit of $\mathbf{1 3}$ showed NOE between $N$-methyl protons at $\delta 3.17$ and aromatic protons at $\delta 7.38\left(2^{\prime}, 6^{\prime}\right)$, indicating that $\triangle \mathrm{MeTyr}$ has the $Z$ configuration as shown. On the other hand, 14 showed NOE between $N$-methyl protons at $\delta 3.14$ and the $\beta$-olefin proton at $\delta 6.63$, indicating that $\Delta \mathrm{MeTyr}$ has the $E$ configuration as shown.

15) Forbes W. F., "In Steric Effects in Conjugated Systems," ed. by Gray G. W., Butterworths, London, 1958, p. 62.

16) Shimohigashi Y., Lee S., Aoyagi H., Kato T., Izumiya N., Int. J. Pept. Protein Res., 10, 323-327 (1977). 